اثر هيوميك اسيد و فولويك اسيد بر برخى ويزگى هاى فيزيولوزيك دو گياه زينتى شمعدانى (Scindapsus spp.) و سيندايسوس (Plargonium spp.)

رسول عباسزاده فاروجى'، محمود شور'"، على تهرانىفر 'و بهرام عابدى'

(تاريخ دريافت: Y (

جكيده

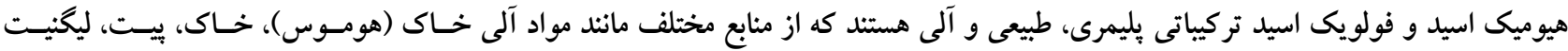

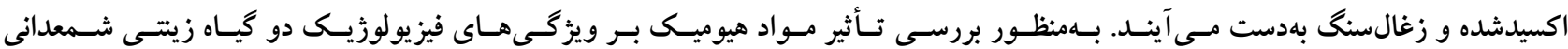

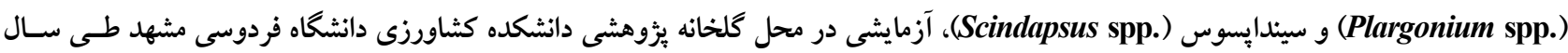

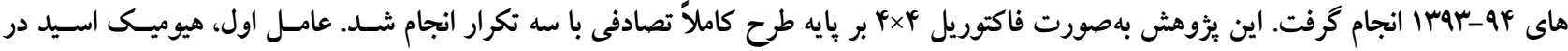

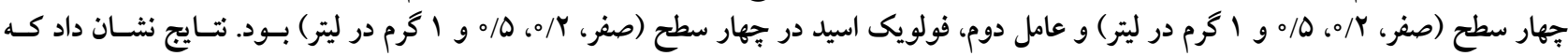

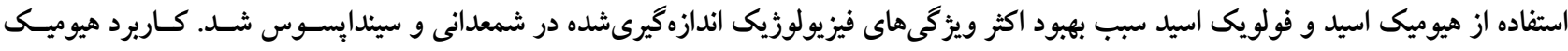

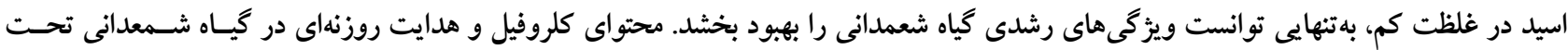

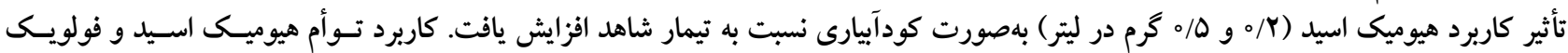

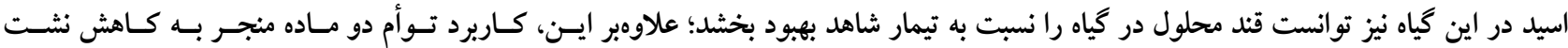

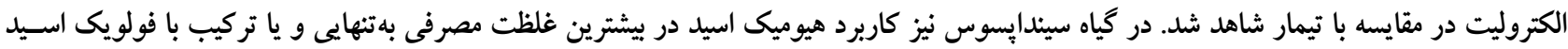

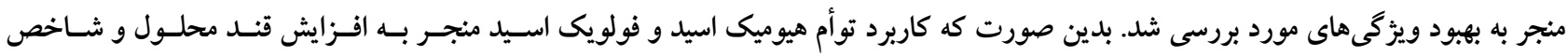

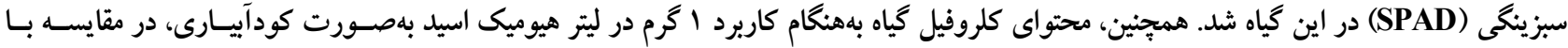

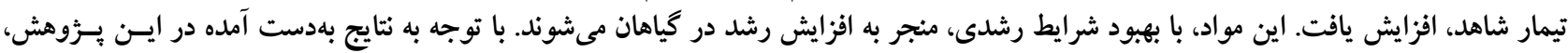

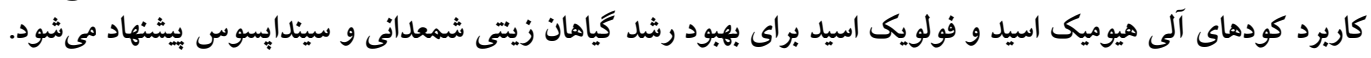

وازمهاى كليدى: كودهاى آلى، ويثَىهاى رشدى، محتواى كلروفيل، هدايت روزنهاى

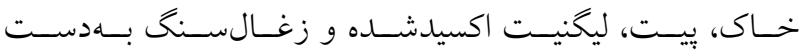

مقدمه

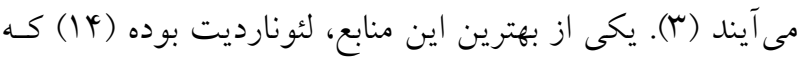

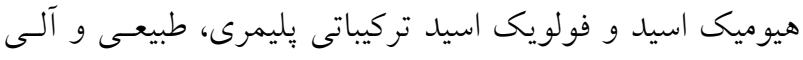

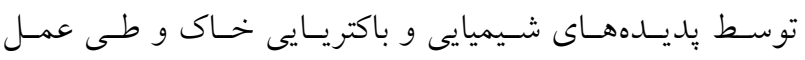

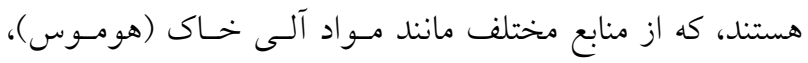

1. كروه علوم باغبانى و مهندسى فضاى سبز، دانشكده كشاورزى، دانشكاه فردوسى مشهد

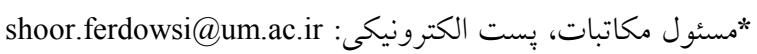




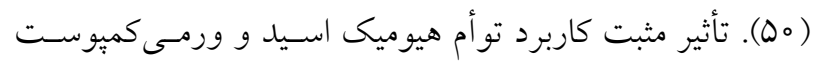

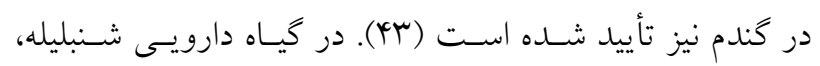

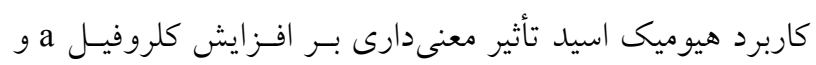

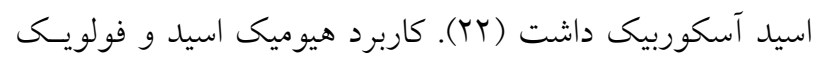

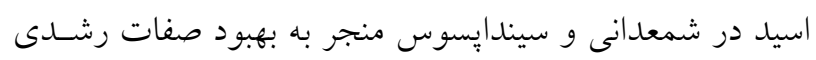

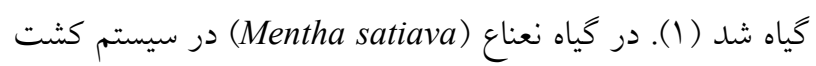

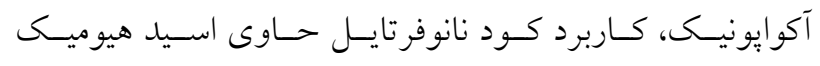

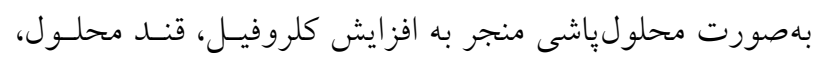

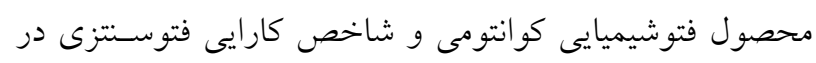
مقايسه با تيمار شاهد شد (هم).

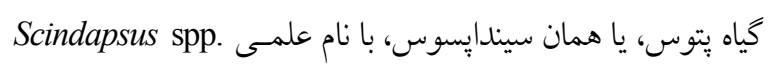

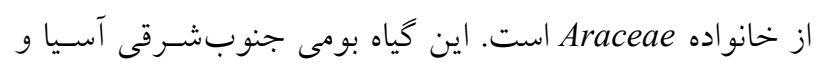

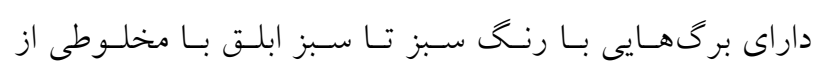

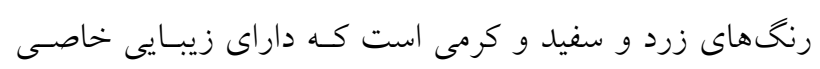

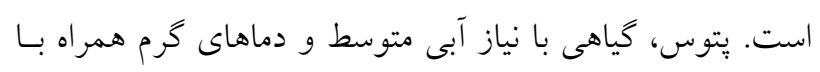

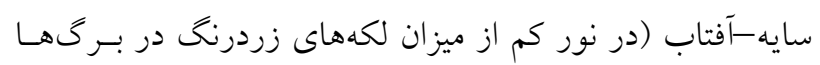

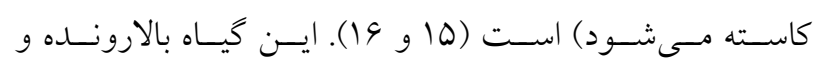

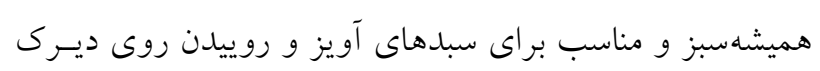

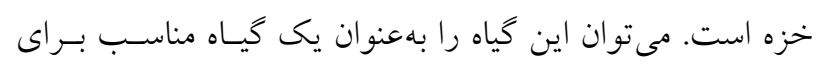

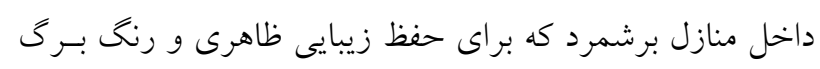

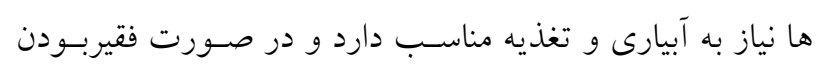
خاك و نامناسب بودن شرايط محيطى رشد سبب كاهش كيفيـت

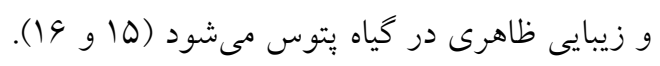

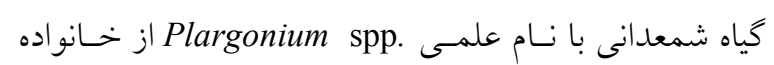
Geraniaceae

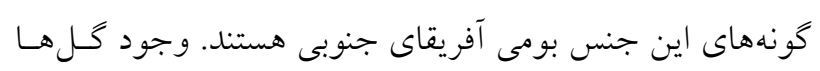

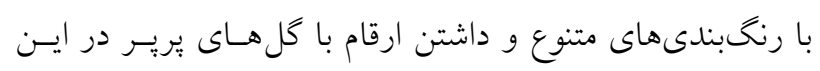

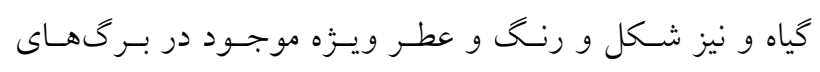

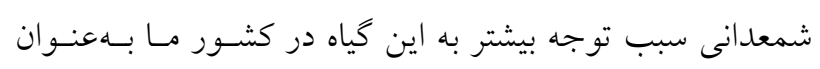

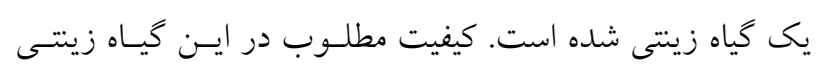

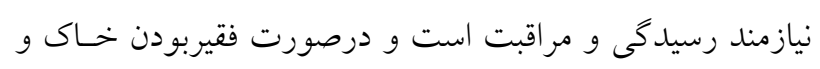

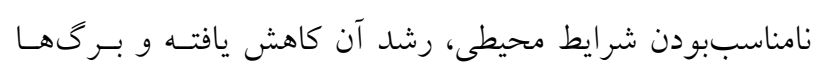

هوموفيكاسيون حاصل مىشود ( (أ). فعاليتهاى زياد ميكروبسى در مواد هوموسى باعث توليد تنظيمكندههاى رشد مانند اكسين،

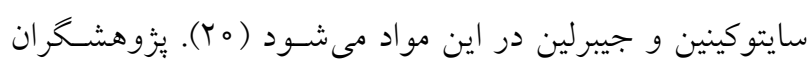
كزارش كردهاند كه كاربرد هيوميكى اسـيد سـبب بهبـود تهويسه

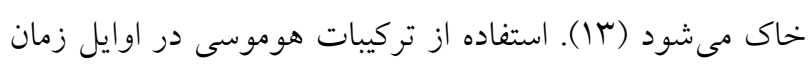

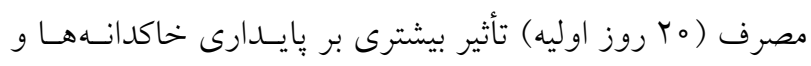

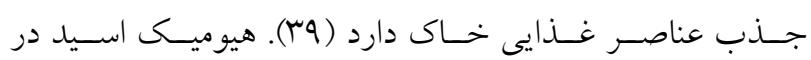

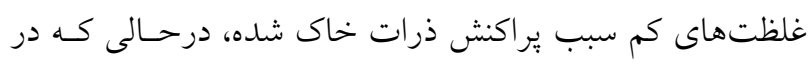

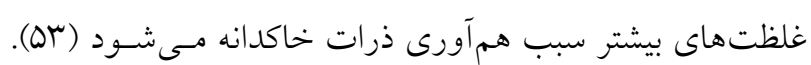

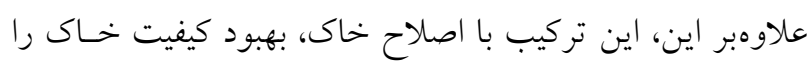

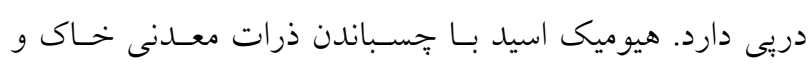

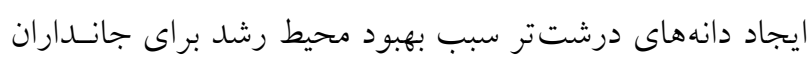

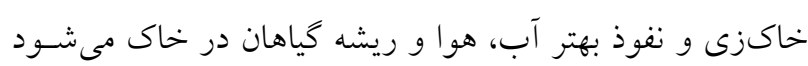

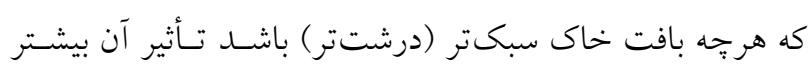

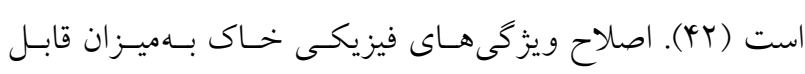

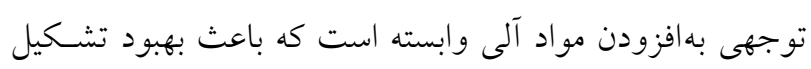

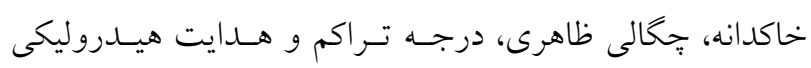

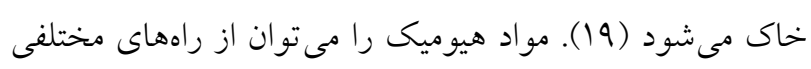

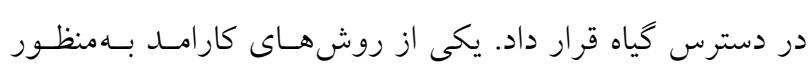

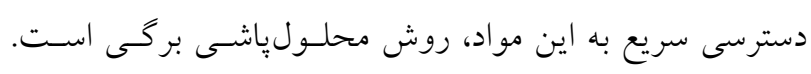

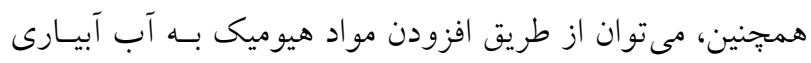

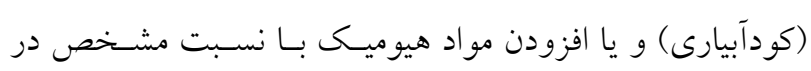

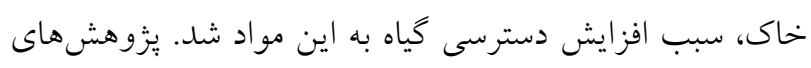

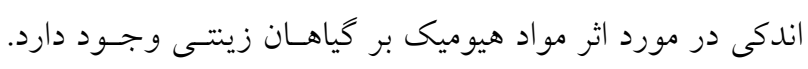

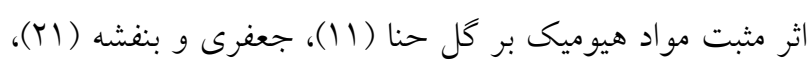

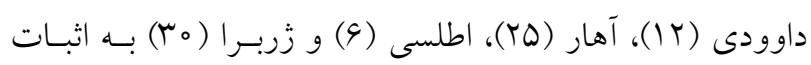

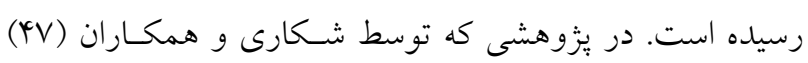

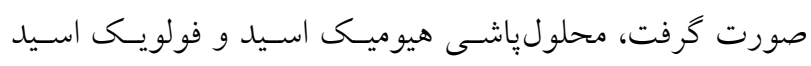

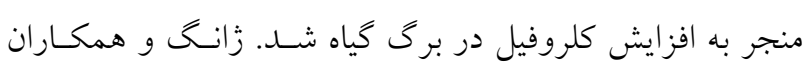

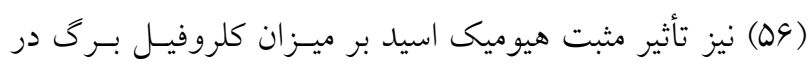

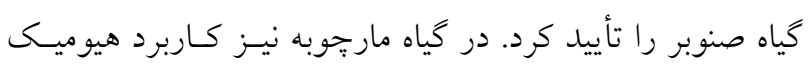

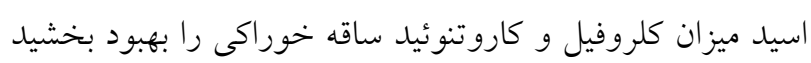


برگ بهمدت ثY ساعت در آب مقطر غوطهور شده و پِ از آن

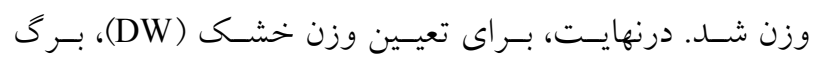

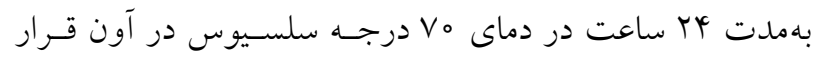

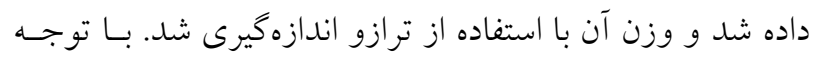

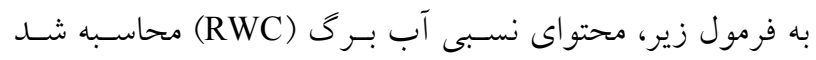

$$
\mathrm{RWC}(\%)=[(\mathrm{FW}-\mathrm{DW}) /(\mathrm{TW}-\mathrm{DW})] \times 100
$$

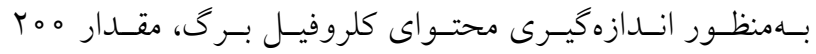

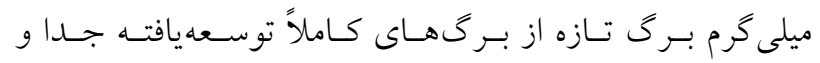

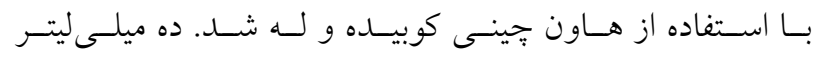

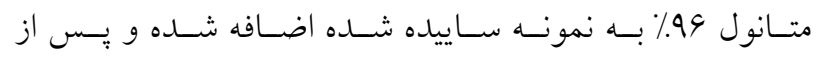

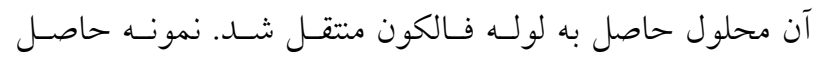

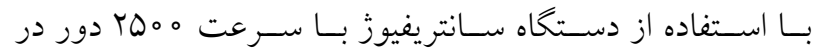
دقيقه بـهــــت ما دقيقـه سـانتريفيوز شـــ از محلـول شـفاف

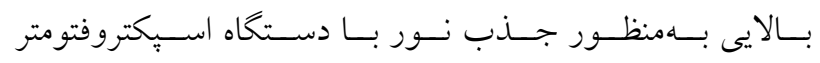
Yvo در طـول مـوجهـاى 904 949 2502, England)

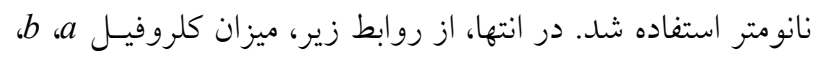

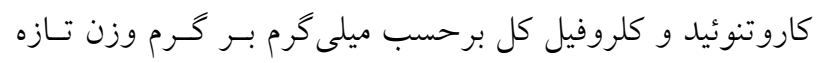

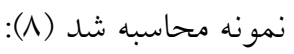

$$
\begin{aligned}
& \mathrm{CHL}_{\mathrm{a}}=10 / 90 \mathrm{~A}_{999}-V / r 4 \circ \mathrm{A}_{90 r}
\end{aligned}
$$

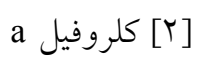

$$
\begin{aligned}
& \mathrm{CHL}_{\mathrm{b}}=r V / \circ \Delta \mathrm{A}_{\varphi \Delta r}-11 / r / \mathrm{A}_{\varphi \varphi \varphi} \\
& \text { [r] كلروفيل } \\
& \mathrm{CHL}_{\mathrm{t}}=\mathrm{CHL}_{\mathrm{a}}+\mathrm{CHL}_{\mathrm{b}} \\
& \text { ] [ب] كلروفيل كل دلروفي }
\end{aligned}
$$

管

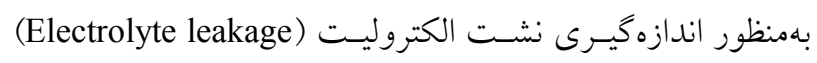

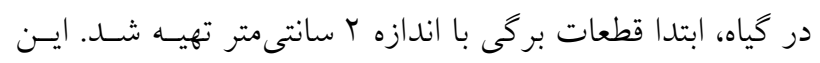

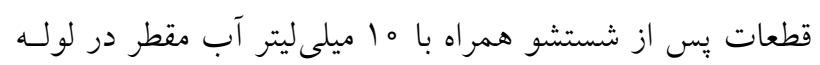

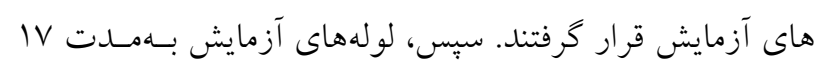

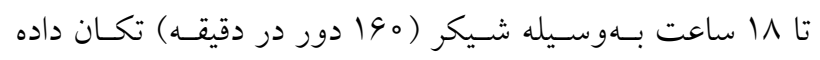

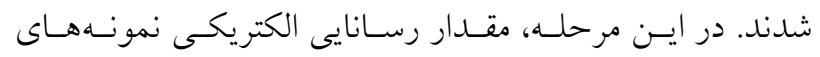

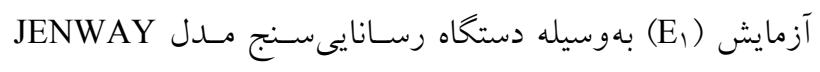

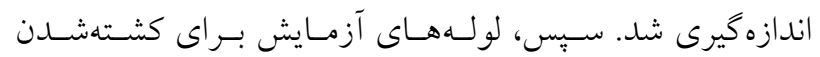

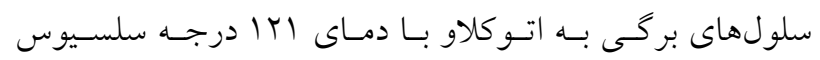

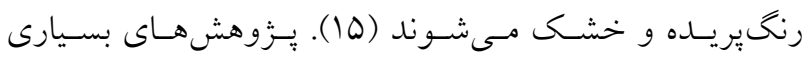

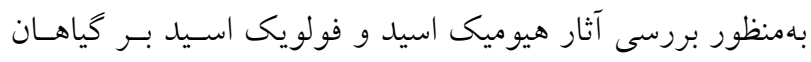
زراعى و باغى صورت گرفته است. اما دانستهاى كمى در مورد مورد

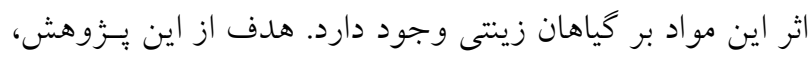

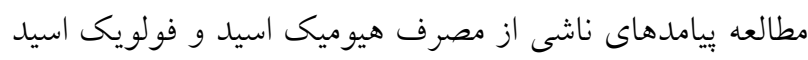

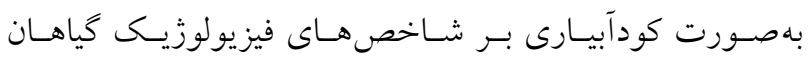

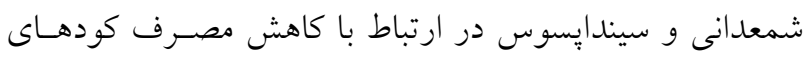

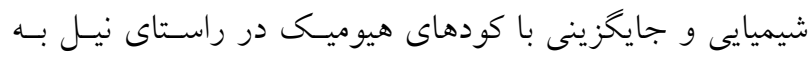
كشاورزى يايدار است.

\section{مواد و روشها - ماد}

بهمنظور بررسى تـأثير مـواد هيوميكى بـر صـفات فيزيولوزيـــ

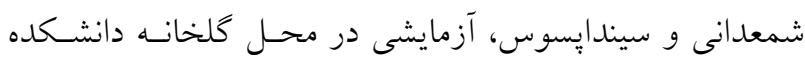

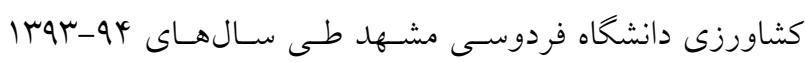

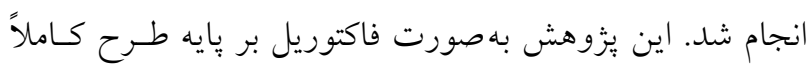

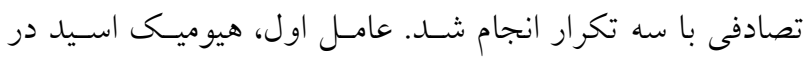

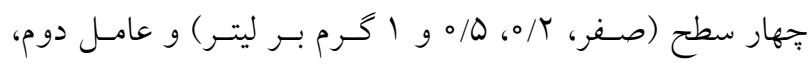

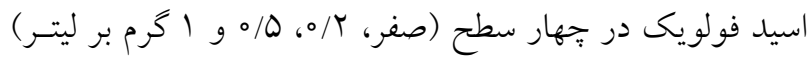

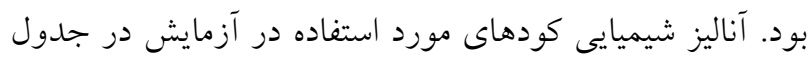
(1) نشان داده شده است. در اواخر اسفندماه، قلمه كيرى از گيـاه

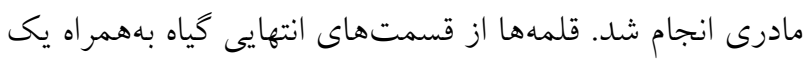

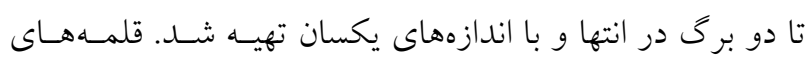

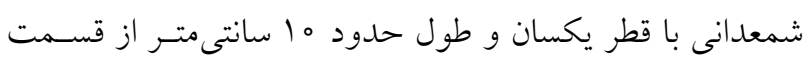

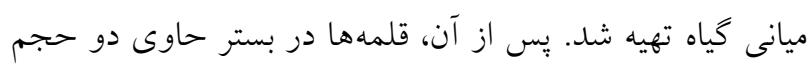

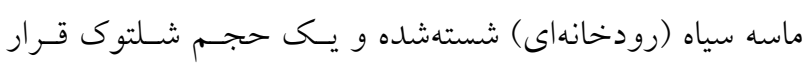

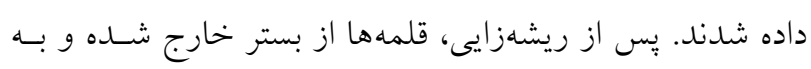

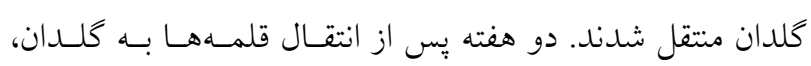

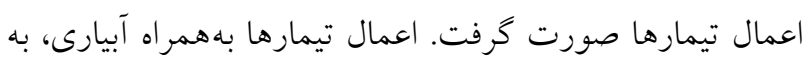

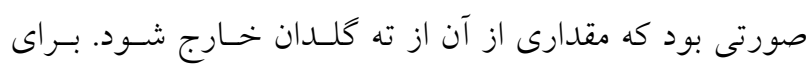

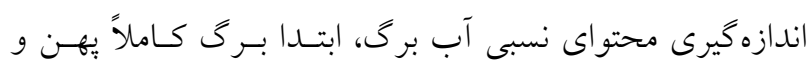

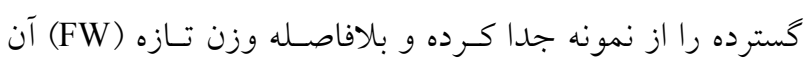

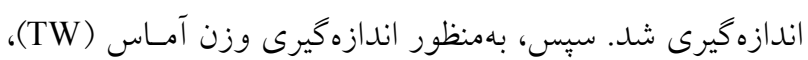


جدول ا. مشخصات كودهاى آلى هيوميك اسيد و فولويك اسيد مورد استفاده در آزمايش

\begin{tabular}{|c|c|c|c|c|c|}
\hline كشور سازنده & فرم كود آلى & حلاليت در آب & $\mathrm{pH}$ & درجه خلوص & نوع كود آلى \\
\hline ايتاليا & دانهاى & $\%$.^D & $1-9$ & $\% \wedge \Delta$ & هيوميك اسيد \\
\hline آلمان & يودرى & $\% \wedge \Delta$ & 9 & $\%$. & فولويك اسيد \\
\hline
\end{tabular}

(SPAD 502 (Konica- Minolta- Tokyo, Japan))

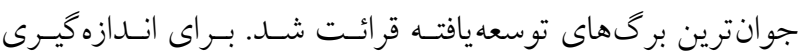
هدايت روزنهاى از دستخاه Leaf porometer مدل SC-1, England

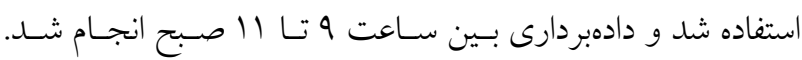
تجزيه آمارى دادهها توسط نرم|فـزار JMP-8 و مقايسـه ميـانكين بـا استفاده از آزمون LSD در سطح احتمال ه.٪ انجام شد. رسم نمـودار با استفاده از نرمافزار 2010 MS Excel صورت گرفت.

\section{نتايج و بحث

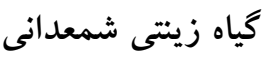

نتايج حاصل از تجزيه واريـانس دادههـا نشـان داد كـهـ تفـاوت بـين تيمارهاى مورد مطالعـه در تعـدادى از صـفات فيزيولوزيـك در دو

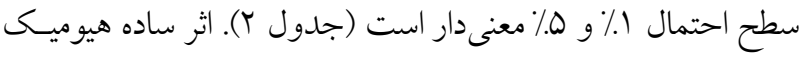
اسيد بـر صـفات قنـــ محلـول، كلروفيـل a، كلروفيـل كـل، نشـت الكتروليت و هدايت روزنهاى در سـطح احتمـال 1\% و بـر صـفات كلروفيل b، كاروتنوئيد و شاخص سـبزينكى در سـطح احتمـال ه.٪ معنى دار اسـت. اثـر سـاده فولويـك اسـيد تنهـا بـر صـفات نشـت الكتروليت و هدايت روزنهاى در سطح احتمال 1٪ معنى دار شد. در صفات هدايت روزنهاى و نشت الكتروليت، اثر برهمكنش هيوميك اسيد و فولويكى اسيد در سطح احتمال I٪ و در صفت قند محلـول در سطح احتمال ه.\% معنىدار شد (جدول r).

$$
\text { نشت الكتروليت }
$$

با توجه به نتايج تجزيه واريانس دادهها مشخص شد كه كـاربرد تركيبى هيوميك اسيد و فولويك اسيد بر ميزان نشت الكتروليت

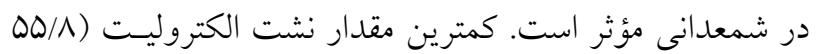
درصد) در تيمار كاربرد توأم ه/ه گرم در ليتر هيوميـك اسـيد و
بهمدت ها دقيقه انتقال داده شدند. بـــين طريـق، انـدازه گيـرى رسانايى الكتريكى در اين مرحله نيز يس از سردشدن محتويات درون لولههاى آزمايش انجام يـــيرفت (EY). درنهايـت، مقـادير

نشت الكتروليت با استفاده از رابطه زير محاسبه شد (سT). $\operatorname{EL}(\%)=\left(E_{1} / E_{Y}\right) \times 10 。$

براى اندازه گيرى قند محلول، ابتدا عصاره بركى تهيه شد. بـراى

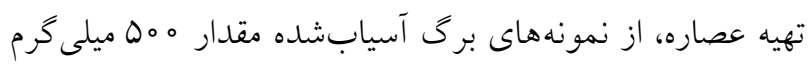
وزن شد و توسـط ه ميلسىليتـر متـانول ه 9٪ اسـتخراج عصـاره

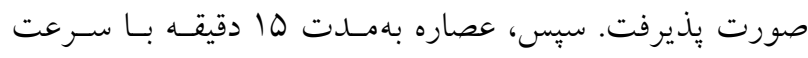

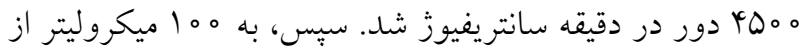

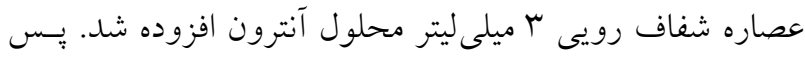

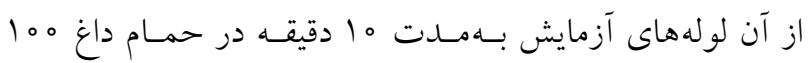
درجه قرار گرفتند. لولهها از حمام داغ درآورده شـده و يـس از ســرد شــدن در طــول مــوج ه广و نــانومتر توســـ دســـاه اسجكتروفتومتر (CE 2502, England) خو انـده شـــ. در نهايـت، ميزان قند محلول برحسب ميلى گرم بر گـرم وزن تـازه محاسـبه شد (Y). بهمنظور اندازهگيرى فنل كل در گياه، در لوله آزمـايش، به 1/ه ميلى ليتر عصاره اتانولى (با غلظت ا ميلى گـرم بـر ميلى

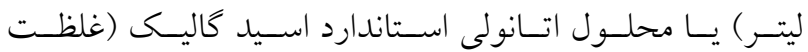

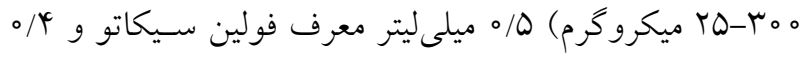
ميلى ليتر كربنات سديم V/D درصد افزوده شده و مخلـوط شـد.

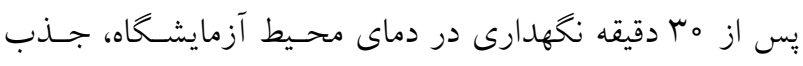
نورى آن توسط دستخاه اسـيكتروفتومتر (CE 2502, England)

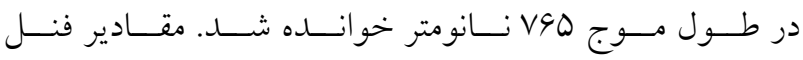
كـل در نمونسههـاى عصـاره بــا اسـتفاده از منحنسى اسـتاندارد برحسـب ميلى گـرم اسـيد كاليـك در خـرم عصـاره بيـان شــ

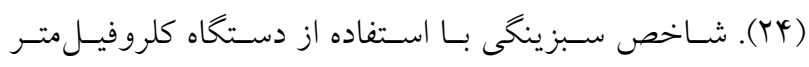


جدول r. تجزيه واريانس (ميانگين مربعات) اثر تيمارهاى مورد بررسى بر صفات فيزيولوزيك اندازهيرىشده در گياه شمعدانى

\begin{tabular}{|c|c|c|c|c|c|c|c|c|c|c|}
\hline روزنهايت & شبزينخى & الكتروليت & كاروتنوئيد & كلروفيل & كلروفيل & $\begin{array}{c}\text { كلروفيل } \\
a\end{array}$ & قحلد & 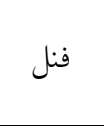 & آزادى درجه & منابع تغييرات \\
\hline $94,4 / 19^{* *}$ & $\Psi V / G Y^{*}$ & rTr/r & $\circ / \wedge V^{*}$ & WI/TV** & $1 / 99^{*}$ & $19 / 9^{* *}$ & $\varphi / T Q^{* *}$ &.$/ 9 \Lambda^{\mathrm{ns}}$ & $r$ & هيوميك اسيد \\
\hline rqYo/rT"** & $r \varphi /\left.T\right|^{\text {ns }}$ & $\Lambda Y / 90^{* *}$ & $\circ / T \Delta^{\mathrm{ns}}$ & $r / r Y^{n s}$ & $\circ / \circ \mathrm{Vns}$ & $Y / \circ \wedge^{n s}$ & $\circ / 9 \circ \mathrm{os}$ & $\circ / V^{n s}$ & $r$ & فولويك اسيد \\
\hline MAYT/YQ** & $14 / 0 V^{n s}$ & rGN/4\%** & $\circ / \mu_{\circ} \mathrm{ns}$ & $r / r I^{\text {ns }}$ & $\circ /\left.\Lambda\right|^{\mathrm{ns}}$ & $\circ / 9)^{\mathrm{ns}}$ & $1 / 49^{*}$ & $1 / \circ r^{\mathrm{ns}}$ & 9 & هيوميك اسيدلفولويكى اسيد \\
\hline rर\&/99 & $9 / 1 V$ & IV/AY & $0 / \pi$ & $r / \Lambda_{0}$ & $\circ / 0 \circ$ & $1 / \Lambda \circ$ & $\circ / \Delta V$ & o/Q & rT & خطا \\
\hline
\end{tabular}

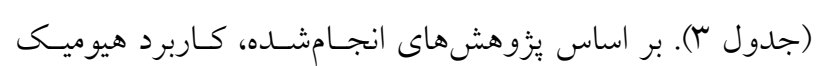

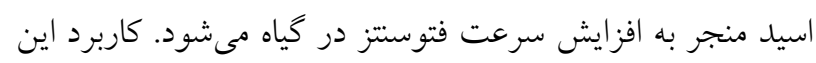

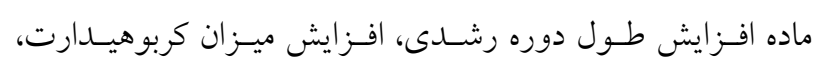

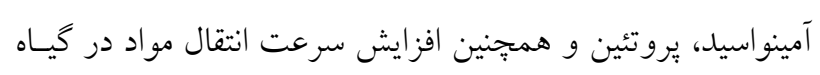

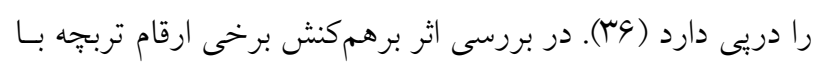

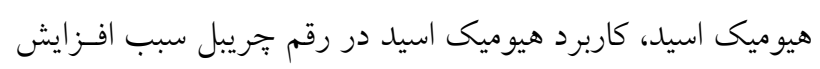

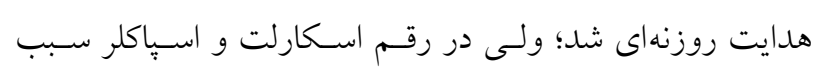

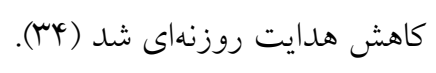

\section{محتواى كلروفيل گياه}

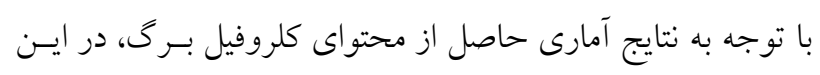

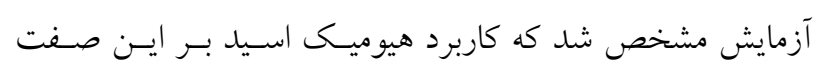

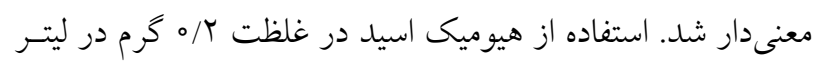
سبب افزايش ميزان كلروفيل a، كلروفيل b و كاروتنوئيسـ در كيـاه

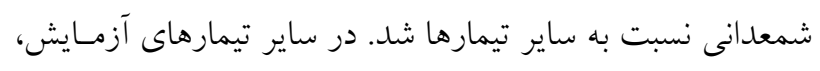

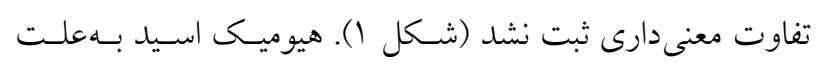

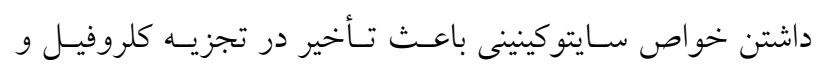

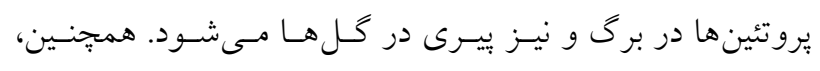

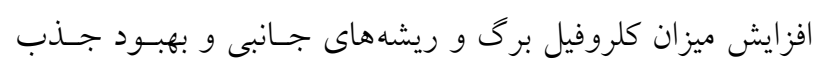

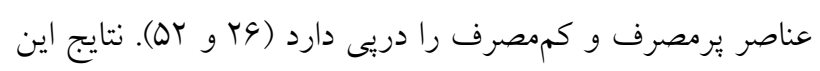

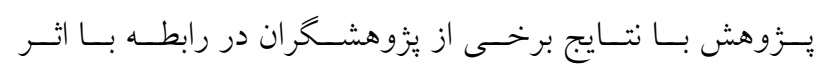

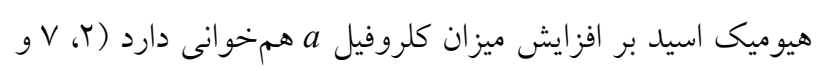

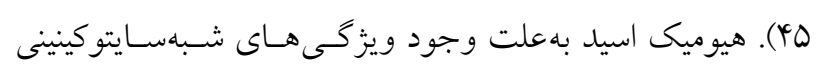

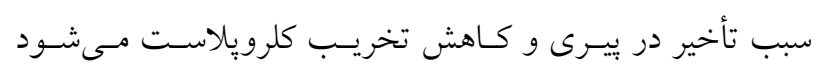

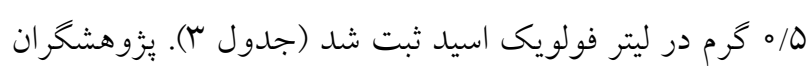

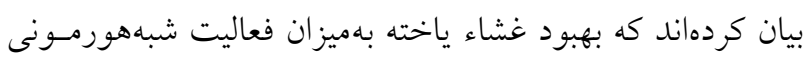

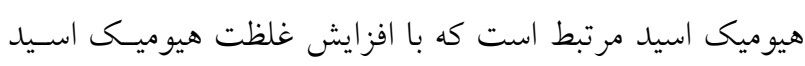

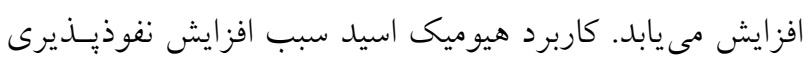
غشاء سلولى و كاهش نشت يونى مىشود (م) (1).

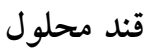

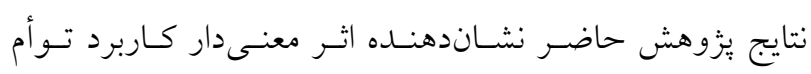

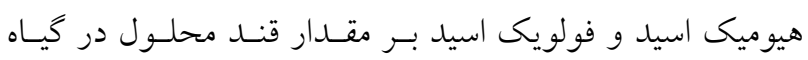
است. كاربرد مواد هيوميك (هيوميكى اسـيد و فولويـك اسـيد)

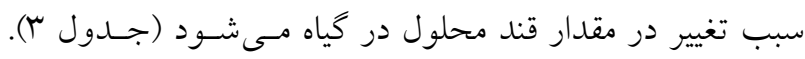

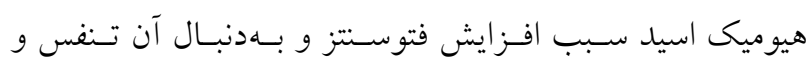

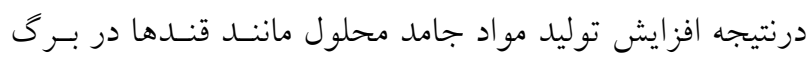

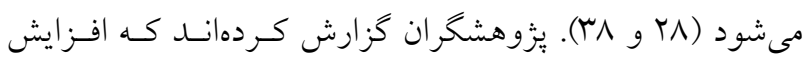

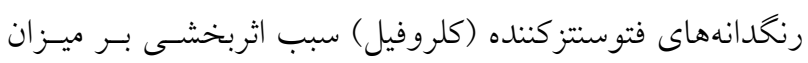

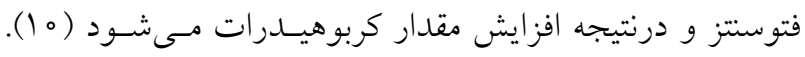

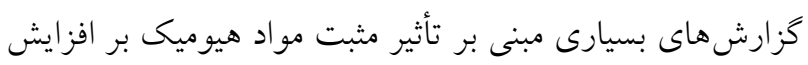

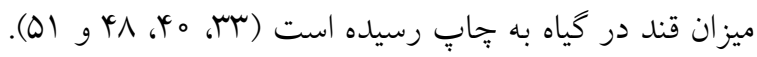

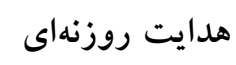

نتايج تجزيه و تحليل آمارى هدايت روزنهاى بيانكر آن بود كه اثر

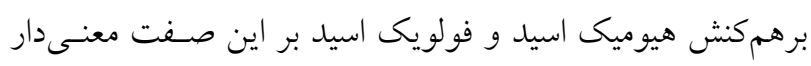

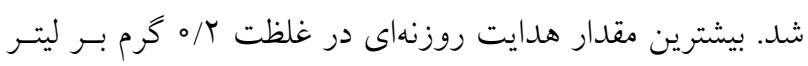

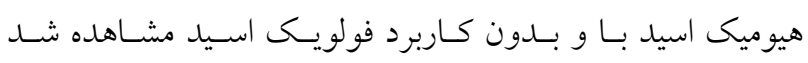




\begin{tabular}{|c|c|c|c|c|}
\hline $\begin{array}{l}\text { قند محلول } \\
\text { (mg/g FW) }\end{array}$ & نشت الكتروليت & $\begin{array}{l}\text { هدايت روزنهاى } \\
\left(\mathrm{mmol} / \mathrm{m}^{r} . \mathrm{s}\right)\end{array}$ & فولويك اسيد & $\begin{array}{c}\text { هيو ميك اسيد } \\
\text { (g/L) }\end{array}$ \\
\hline $4 / 0 r^{\mathrm{b}-\mathrm{e}}$ & $90 / 9 \mathrm{~g}$ & 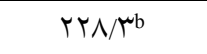 & 。 & \multirow{4}{*}{$\circ$} \\
\hline$q / 4 q a-c$ & $\Lambda \mathrm{V} / \mathrm{V}^{\mathrm{a}}$ & $r \circ r / Y^{b-d}$ & $0 / r$ & \\
\hline$\Delta / \circ V^{d e}$ & $19 / 9^{a}$ & $r_{\circ} \circ / r^{b-d}$ & $\circ / 0$ & \\
\hline$V / q 4 a$ & $9 \circ / 1^{a}$ & $r Y \circ / c^{c b c}$ & 1 & \\
\hline$q / 1 \mathrm{r}^{\mathrm{b}-\mathrm{d}}$ & $V y / o^{d-f}$ & $r ৭ \& / 0^{a}$ & 。 & \multirow{4}{*}{$0 / r$} \\
\hline$\Delta / \mathcal{A} \Delta^{c-e}$ & $V G / q c-e$ & $r \circ 9 / r^{b c}$ & $0 / Y$ & \\
\hline $9 / 0)^{\mathrm{a}-\mathrm{c}}$ & $V G / q^{c-e}$ & $\mid \Delta Y / \gamma^{f g}$ & $\circ / 0$ & \\
\hline $4 / 9 V^{a b}$ & $q \mathcal{H}^{\mathrm{N}} \mathrm{g}$ & $|V| /\left.\right|^{d-f}$ & 1 & \\
\hline $0 / \circ q$ de & $\Lambda r / 4 a-c$ & $|\mathrm{~F} /|_{\mathrm{fg}}$ & $\circ$ & \multirow{4}{*}{$\circ / 0$} \\
\hline Y/Are & $\wedge \Delta / \vee^{\mathrm{ab}}$ & $109 / 1^{\mathrm{e}-\mathrm{g}}$ & $0 / r$ & \\
\hline$\Delta / r q c-e$ & $\Delta \Delta / \wedge^{\mathrm{h}}$ & $19 r / 9 \mathrm{e}-\mathrm{g}$ & $\circ / 0$ & \\
\hline$Q / \circ Y^{\mathrm{de}}$ & $V q / q^{b-e}$ & $\mid F Y / \circ f g$ & 1 & \\
\hline $0 / 4 q c-e$ & $\Lambda \circ / \Delta^{b-d}$ & $19 r / \mathrm{cc}^{\mathrm{c}-\mathrm{e}}$ & $\circ$ & \multirow{4}{*}{1} \\
\hline$\Delta /\left.4\right|^{c-e}$ & $V r / Y_{\text {ef }}$ & $\mid \mu \wedge / \mu g$ & $0 / Y$ & \\
\hline $4 / 11^{b-d}$ & $V q / c^{c b-e}$ & $\zeta \circ \circ / Y^{b-d}$ & $\circ / 0$ & \\
\hline$Q / / /$ de & $9 \wedge / \Delta^{f g}$ & $190 / \mathrm{r}^{\mathrm{c}-\mathrm{e}}$ & 1 & \\
\hline
\end{tabular}

در هر ستون، ميانخينهاى با حداقل يك حرف مشترى، اختلاف معنىدارى در سطح هـ٪ بر اساس آزمون LSD ندارند.

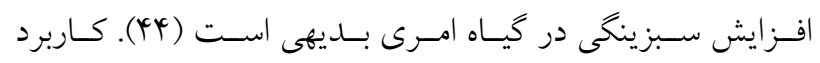

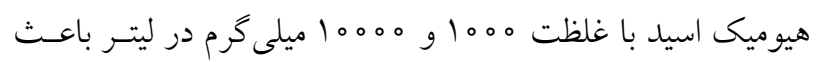
كاهش ميزان كلروفيل در گل بريده آلستروميا شد (ه). نتايج تجزيـه واريـانس دادههـا نشـان داد كـه تفـاوت بـين تيمارهاى مورد مطالعسه در تعـدادى از صـفات فيزيولوزيـك در

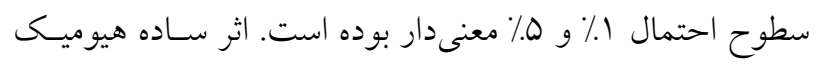
اسيد بر صفات شاخص سبزينگى، كلروفيل b و كلروفيل كل در سطح احتمال 1\% و بر صفات كاروتنوئيد برگ و كلروفيـل a در سطح احتمال ه.٪ معنى دار شد. همجنين، اثر ساده فولويك اسـيد بر صفات فنل، قند محلول، كلروفيل b، كاروتنوئيــ و كلروفيـل كـل در سـطح احتمـال ا٪ و بـر صـفت كلروفيـل a در سـطح احتمـال ه٪٪ معنسى دار شـــ در صـفات مقــدار فنـل، تركيبـات
(OS). ئزوهشخران نشان دادهاند كـه كـاربرد هيوميـك اسـيد روى

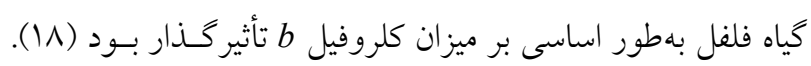

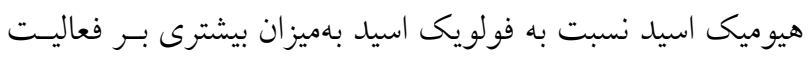

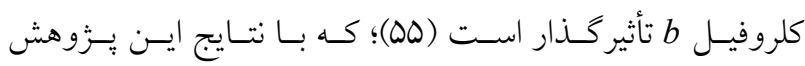
همخوانى دارد. همجنين هيوميك اسيد با كـاهش pH آيويلاسـت برگ، سبب افزايش فعاليت آنزيمى روى غشــاء سـلول مسى هــود. درنتيجه اين اثر سبب تبديل آهن به فرم قابل جذب و قابل انتقـال آن از غشاء سلول مىشود و از اين طريق كلروز ناشسى از كمبـود آهن را رفع نموده و سبب حفظ كلروفيـل بـرى مسى شـود (MY). افزايش جذب عناصر غذايى در اثر كاربرد هيوميك اسيد در گيـاه منجر به افزايش جذب نيتـروزن در كيـاه مسىشـود. در نتيجـهـ بـا افزايش ميـزان جـــب نيتـروزن كيـاه افـزايش ميـزان كلروفيـل و 

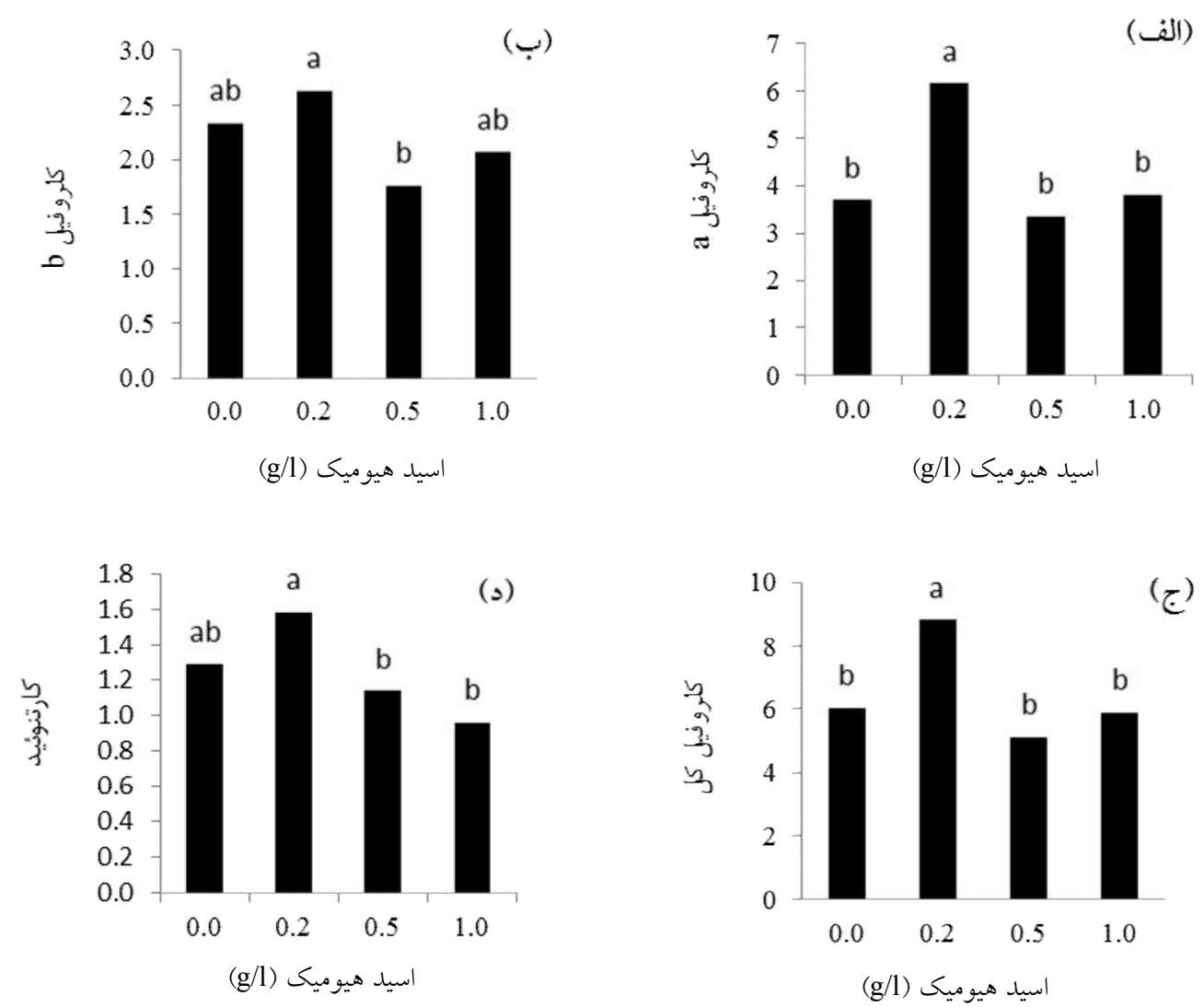

شكل l. مقايسه ميانگين اثر كاربرد هيوميك اسيد (g/L) بر الف) كلروفيل a، ب) كلروفيل b، ج) كلروفيل كل و د) كاروتنوئيد در گياه

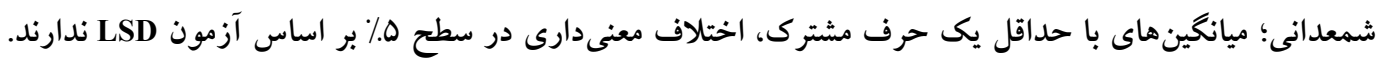

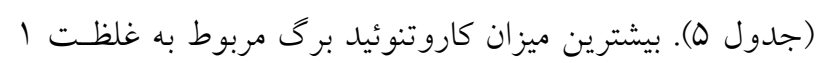

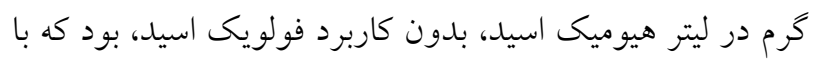

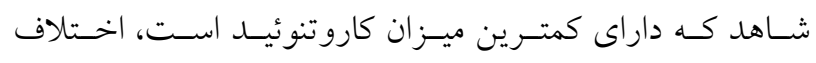

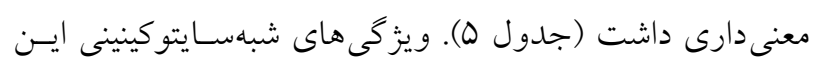

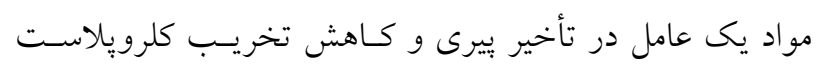

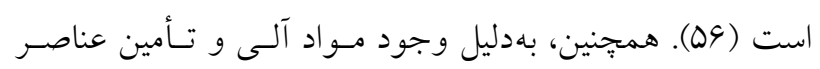

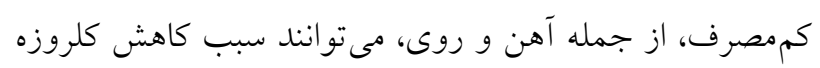

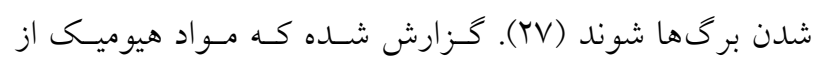

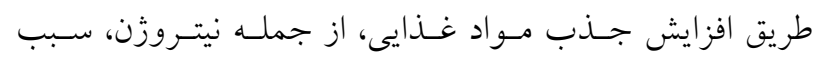

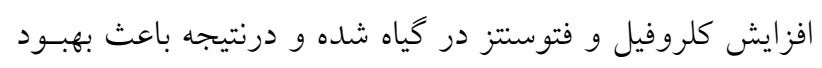

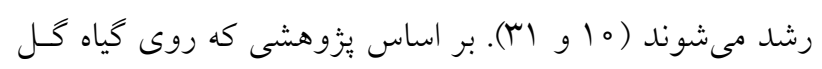

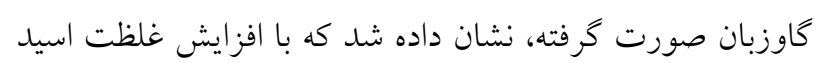

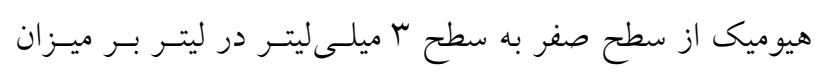

قندى، كلروفيل b، كاروتنوئيد و كلروفيل كـل، اتـر بـرهمكــش هيوميك اسيد و فولويكى اسيد در سطح احتمال اء و و در صفات

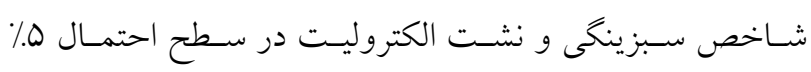

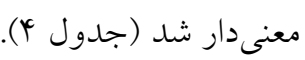

\section{محتواى كلروفيل برى}

نتايج حاصـل از انــازهذيـرى محتـواى كلروفيـل بــرى بيـانكر

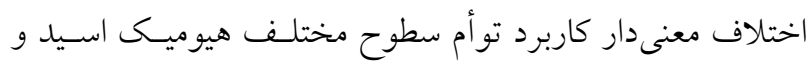

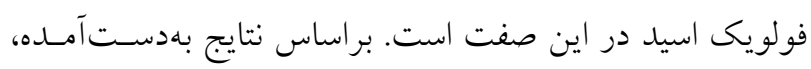

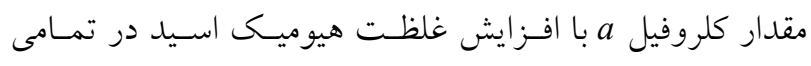

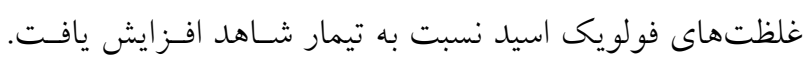

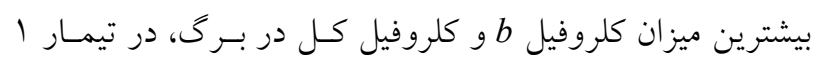

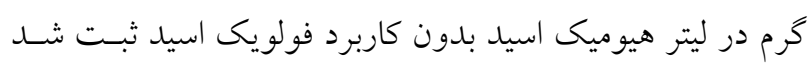


جدول ع. نتايج تجزيه واريانس (ميانخين مربعات) اثر تيمارهاى مورد بررسى بر ويزگىهاى فيزيولوزيك اندازگيرىشده در گياه سيندايسوس

\begin{tabular}{|c|c|c|c|c|c|c|c|c|c|c|}
\hline الكتروليت & آنسبى نحتواى & كلروفيل & كاروتنوئيد & كلروفيل & كلروفيل & سبزينگى ساخص & قند & 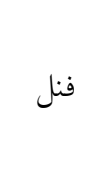 & آزادى درجه & منابع تغييرات \\
\hline$V / V Y^{n s}$ & $9 / T V^{n s}$ & $r I / N \mu^{* *}$ & $1 / 10^{*}$ & $\Lambda / \circ r^{* *}$ & $r / Q q^{*}$ & $91 / 1 V^{* *}$ & $\circ / \Lambda q^{\mathrm{ns}}$ & $\circ / 99^{\text {ns }}$ & r & هيوميك اسيد \\
\hline$r / r q^{n s}$ & $19 / 19^{\mathrm{ns}}$ & $1 \% / 10^{* *}$ & $1 / 9 V^{* *}$ & $\mathrm{~V} / \circ \wedge^{* *}$ & 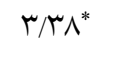 & $V / \Delta \Delta^{\mathrm{ns}}$ & $\Delta / V Q^{* *}$ & $9 / 99^{* *}$ & r & فولويك اسيد \\
\hline $\mathrm{V} / \mathrm{AV}$ & $4 / r \Delta^{\mathrm{ns}}$ & $\mid \Psi / N r^{* *}$ & $1 / \Delta r^{* *}$ & $9 / 49^{* *}$ & $r / Y_{0} 0^{*}$ & $r \circ / \varphi \psi^{*}$ & $r / \circ D^{* *}$ & $\mathrm{~V} / \mathrm{V} \mathrm{Q}^{* *}$ & 9 & هيوميكاسيد×فولويكاسيد \\
\hline$r / \circ 4$ & N/90 & INV & $\circ / \Lambda$ & $0 / 49$ &.$/ 90$ & $10 / 0 \mathrm{~V}$ & $0 / \mu 1$ & $0 / 90$ & rt & خطbا \\
\hline
\end{tabular}

\begin{tabular}{|c|c|c|c|c|c|c|c|c|c|}
\hline \multirow{2}{*}{ الكتروليت } & كلروفيل & كاروتنوئيد & كلروفيل & كلروفيل & \multirow{2}{*}{ سبزينكى } & محلد & فنل & \multirow{2}{*}{ فولويك اسيد } & \multirow{2}{*}{$\begin{array}{c}\text { هيوميك اسيد } \\
\text { (g/L) }\end{array}$} \\
\hline & \multicolumn{4}{|c|}{ (mg/g FW) } & & \multicolumn{2}{|c|}{$(\mathrm{mg} / \mathrm{g} \mathrm{FW})$} & & \\
\hline $\mid \varphi / r^{a-c}$ & $\psi / \circ \mu^{d-g}$ & $1 / \pi \mu^{e}$ & $r / G \varphi_{\mathrm{c}-\mathrm{e}}$ & $1 / \mu^{\mathrm{cd}}$ & $Y \backslash / v^{c-f}$ & t/NTab & $Q / \circ \nvdash g$ & $\circ$ & $\circ$ \\
\hline $11 /\left.\right|^{\mathrm{cd}}$ & $r / 19^{\mathrm{fg}}$ & $T / \mu Y^{c-e}$ & $1 / 4 \varphi^{\mathrm{fg}}$ & $\circ / N^{\gamma^{d}}$ & $\mathrm{YV} / \mathrm{oab}$ & Y/OQ ef & $\varepsilon / 4 q \mathrm{~d}-\mathrm{f}$ & $0 / r$ & \\
\hline $11 / \wedge^{\mathrm{cd}}$ & $Y / V Y^{c-e}$ & $T / q^{c-e}$ & $r / \Lambda \Gamma^{\mathrm{b}-\mathrm{d}}$ & $1 /\left.9\right|^{b-d}$ & $Y V / c a b$ & $r / 9 \circ \mathrm{of}$ & $G / N r^{\mathrm{c}-\mathrm{e}}$ & $\circ / 0$ & \\
\hline $14 / \wedge^{\mathrm{ab}}$ & $Q /\left.V\right|^{b-d}$ & $r / 4 r a b$ & $r / \Delta \Delta^{c-f}$ & $r / 1 q^{a b}$ & $\varphi \Delta / \wedge^{a-d}$ & $r / 9 \mathrm{Vd}-\mathrm{f}$ & $V / 4 \Lambda^{b-d}$ & 1 & \\
\hline $14 / \Gamma^{a-c}$ & $1 / 90 \mathrm{~g}$ & 1/Q ode & $\circ / 9 r^{g}$ & $\circ / 9 V^{c d}$ & $Y N / I^{a}$ & $4 /\left.9\right|^{a}$ & $\Lambda / V \circ b$ & $\circ$ & $0 / T$ \\
\hline $\mid \mu / /^{a-c}$ & $\varphi / \mu v^{c-f}$ & $r / / Q^{a-c}$ & $r / Y^{c} c^{c-f}$ & $1 /\left.9\right|^{b-d}$ & $|\varphi| / \mu^{c-f}$ & $r / 0 \mu^{c-f}$ & $V / D \cdot b-d$ & $\circ / r$ & \\
\hline $\mid r / N^{a-c}$ & $Y / N^{\mu^{c-e}}$ & $1 / \mathrm{V} \mathrm{de}^{\mathrm{de}}$ & T/99c-e & $r / \circ V^{b-d}$ & $\kappa r / D^{a-d}$ & $r / \Delta \psi^{c b-d}$ & $\Delta / V \varphi^{e-g}$ & $\circ / 0$ & \\
\hline $14 / q^{a b}$ & $Y / \Delta q \mathrm{c-e}$ & $T / T^{c-e}$ & $r / 9 Q^{c-e}$ & $1 / 9 k^{c b-d}$ & $\varphi \varphi / /^{\mathrm{a}-\mathrm{c}}$ & $r / \Lambda \wedge^{f}$ & $\Delta / \mathcal{F} \Delta^{e-g}$ & 1 & \\
\hline $\mathrm{Q} / \mathrm{A}^{\mathrm{d}}$ & $9 / \mu \mathrm{Vbc}$ & $r / 1 q^{a-c}$ & $r / a r^{b}$ & T/Yya-c & $Y Y / A^{a-d}$ & $r / 9 \circ a$ & $1 \circ / \mathrm{rV}^{\mathrm{a}}$ & $\circ$ & $\circ / 0$ \\
\hline $11 /\left.\right|^{\mathrm{cd}}$ & $r / V^{d-g}$ & $r /<q^{a-d}$ & $1 / 9 Y^{\mathrm{e}-\mathrm{g}}$ & $r / / Y^{\mathrm{bb}-\mathrm{d}}$ & $\varphi \circ / \varphi^{\mathrm{d}-\mathrm{f}}$ & $r / 9 \varphi^{c-f}$ & $\Delta / \sim_{G} \mathrm{fg}$ & $0 / r$ & \\
\hline $\mid r / q^{b-d}$ & $r / \Gamma \Lambda^{e-g}$ & $Y / Y Y^{c-e}$ & $1 /\left.\Delta\right|^{e-g}$ & $1 / N^{\mathrm{b}-\mathrm{d}}$ & $k r / \Gamma^{a-d}$ & $r / q V^{b c}$ & $\Delta / r Y^{f g}$ & $\circ / 0$ & \\
\hline $14 / /^{a-c}$ & $\varphi / r \varphi c-f$ & $r / Y<\left.\right|^{b-d}$ & $1 / \Lambda \Upsilon^{\mathrm{d}-\mathrm{g}}$ & $r / \Delta \mu^{\mathrm{a}-\mathrm{c}}$ & $r V / T^{f}$ & $r / \Lambda)^{c-f}$ & $\Delta / \Delta)^{e-g}$ & 1 & \\
\hline $1 r / q^{a-c}$ & $11 / r r^{a}$ & $r /\left.0\right|^{a}$ & $\mathrm{~V} / \Delta \mathrm{ra}^{\mathrm{a}}$ & $r / v q^{a}$ & $\mu \psi / \wedge^{a-d}$ & $r / 4 \& b-\mathrm{e}$ & $\mathrm{V} / /^{\mathrm{cd}}$ & 。 & 1 \\
\hline $10 / 9^{a}$ & $\Delta / \wedge \Upsilon^{b-d}$ & $\Upsilon / \circ \Delta^{a-c}$ & $r / 9 Q^{c-e}$ & $r / l r^{a b}$ & $\hat{Y Y / G b-e}$ & $r / 14^{\mathrm{f}}$ & $V / I Q^{c d}$ & $0 / r$ & \\
\hline $1 \mu / N^{a-c}$ & $r / \Delta V^{e-g}$ & $1 / 9 \varphi^{\mathrm{de}}$ & $1 / V Q^{d-g}$ & $\circ /\left.\mathrm{N}\right|^{\mathrm{d}}$ & $\mathrm{rV} / \mathrm{e}^{\mathrm{ef}}$ & $y / \circ \varphi^{a b}$ & $\varepsilon / T^{d-f}$ & $\circ / 0$ & \\
\hline $1 T / r^{b-d}$ & $V / \omega \circ b$ & $r / r q^{a b}$ & $\Gamma / \Delta \wedge^{\mathrm{bc}}$ & $r / q r^{a}$ & $\varphi / / \Delta^{c-f}$ & $Y / A V^{a}$ & $V / \Lambda)^{4 b c}$ & 1 & \\
\hline
\end{tabular}

در هر ستون، ميانكينهاى با حداقل يك حرف مشترى، اختلاف معنى دارى در سطح ها٪ بر اساس آزمون LSD ندارند.

محتواى كلروفيل a b و كل افزوده شد و با افزايش ميزان اسـيد هيوميك به 9ميلى ليتر در ليتر از ميزان محتواى كلروفيـل كاسـته 
ميزان محتواى كلروفيل بركهاى گياه كوجهفرنخى دريافتند كـه

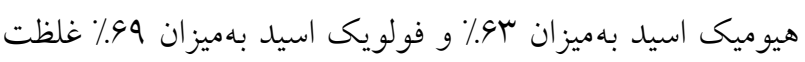

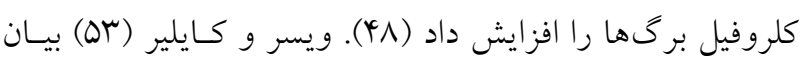

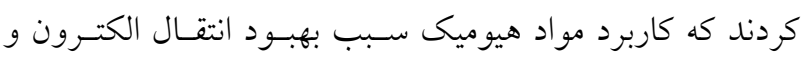
افزايش ظرفيت فتوسنتزى در كياه مى شودد.

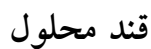
نتايج يزوهش حاضر در ارتباط با قند محلـول نشـاندهنـــه اثـر

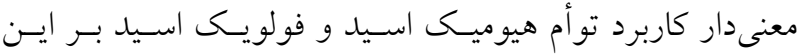

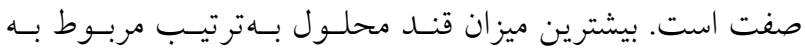

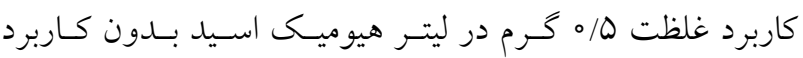

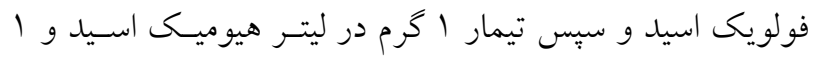

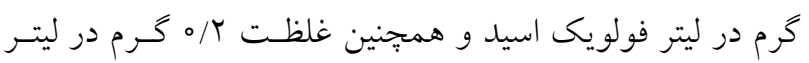

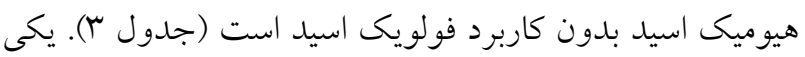

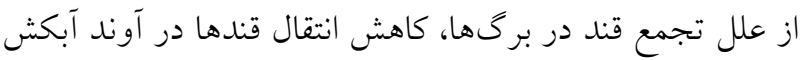

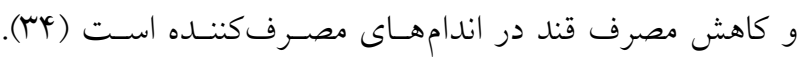

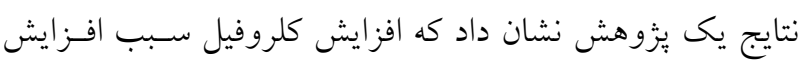
مقدار قند و كربوهيدراتها مى شود. بر اساس بزوهشى كـه در

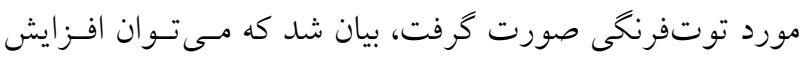

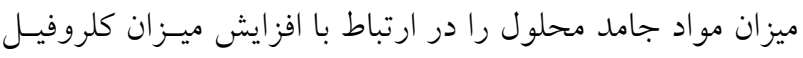

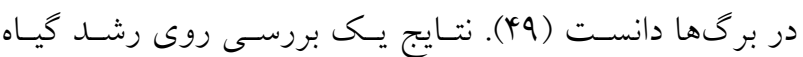

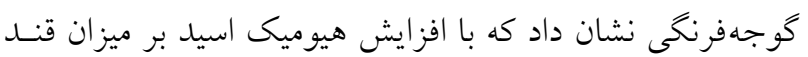
كياه نيز افزوده مىشود (1) (1).

\section{نشت الكتروليت}

نتايج تجزيه و تحليل آمارى نشت الكتروليت بيانكر آن بـود كـهـ

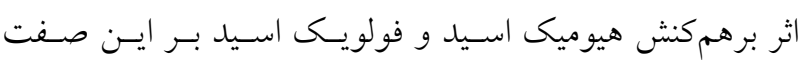
معنى دار بود. كمترين مقدار نشت الكتروليـت در تيمـار كـاربرد

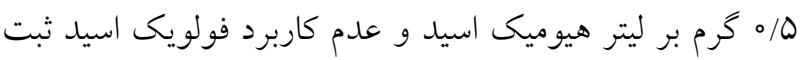

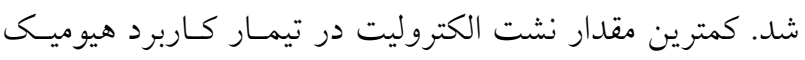

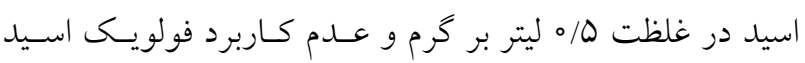
ثبت شد. پِس از اين تيمـار و بـــون اخـتلاف معنسىدار، مقــدار
شد. در يزوهشى، بيـان شـــ كـه كـاربرد هيوميكى اسـيد سـبب

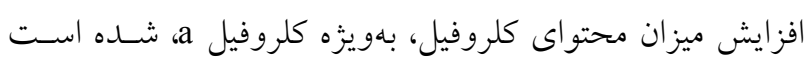

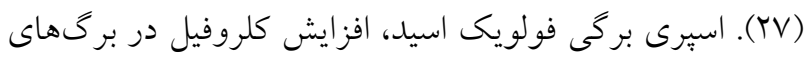

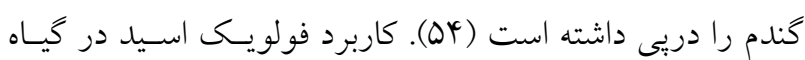

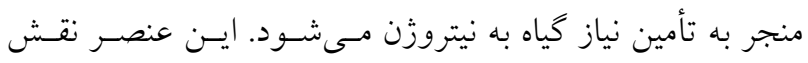

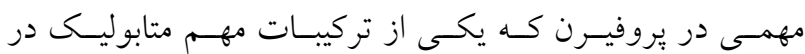

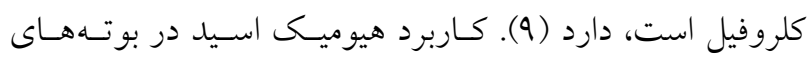

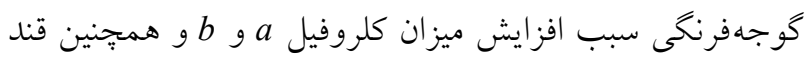

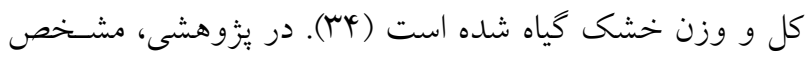
شد كه كاربرد هيوميك اسيد سبب افزايش جذب وز آهن و منخُنز

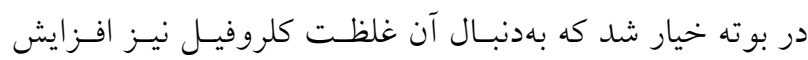
يافت (Tr). يزوهش ها نشـان داده كـه مصـرف هيوميكى اسـيد

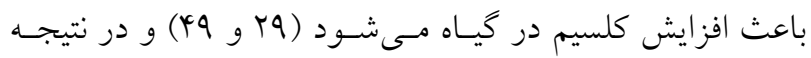

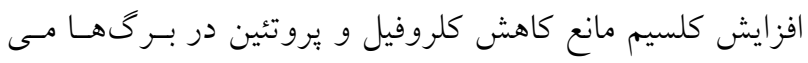

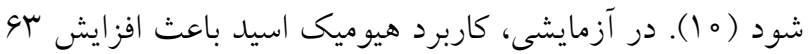

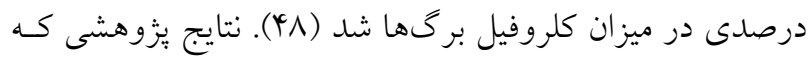

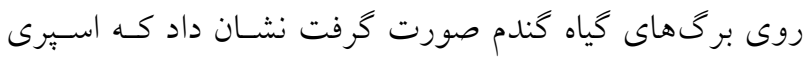

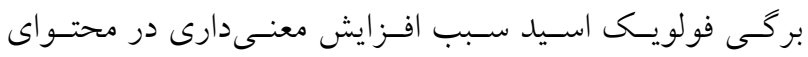
كلروفيل بركها شده است (QF).

\section{شاخص سبز ينكى} نتايج حاصل از آزمايش در ارتباط با شاخص سـبزينكى بيـانكر

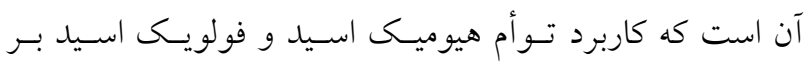

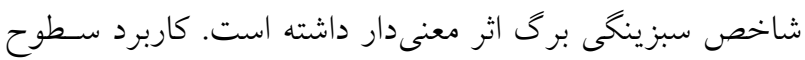

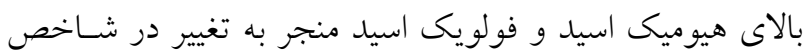

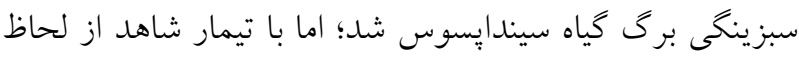
آمارى تفـاوت معنسىدارى نشـان نــاد. كـاربرد سطوح بـايين هيوميك اسيد بههمراه فولويكى اسـيد منجـر بــه افـزايش مقــدار شاخص سبزينگى نسبت به تيمار شاهد شد (جدول ه). كـاربرد

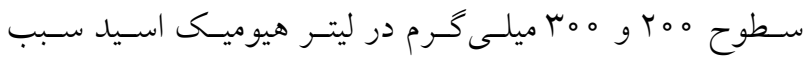

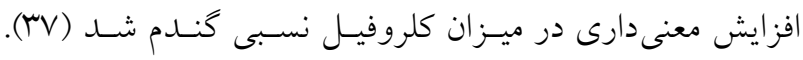

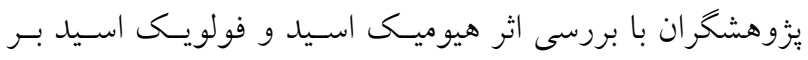




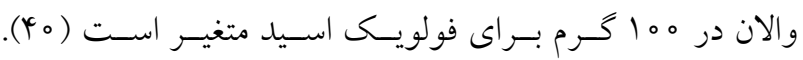

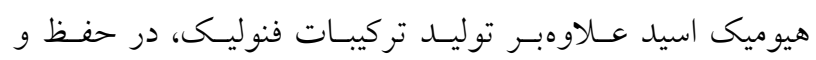

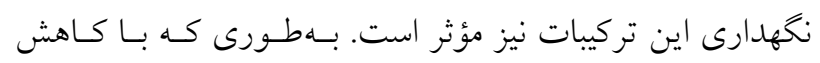

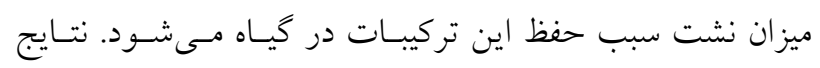

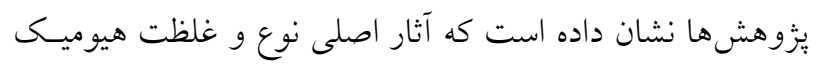
اسيد بر ميزان تركيبات فنوليك معنى دار است (10).

\section{نتيجه گيرى}

با توجه به نتايج بهدست آمده در اين بزوهش، مشخص شئ شد كـه

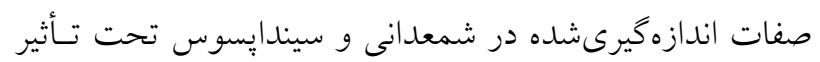
كاربرد هيوميك اسـيد و فولويـك اسـيد قـرار كرفتنــــ كـاربيرد

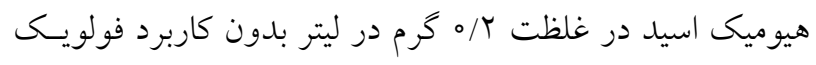

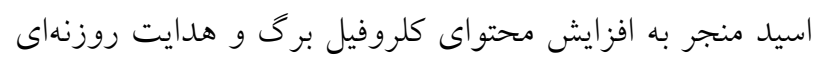

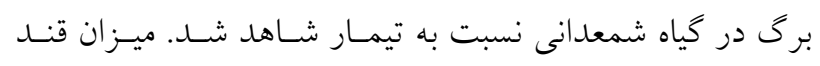

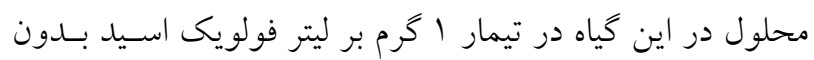

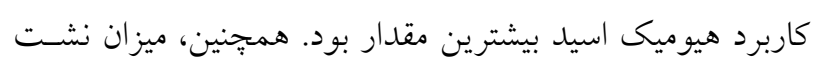

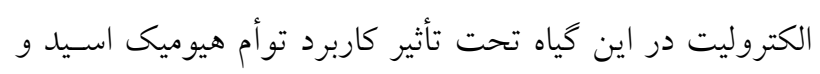

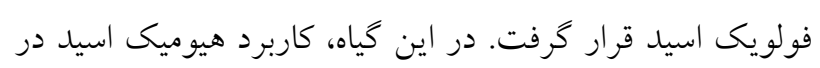

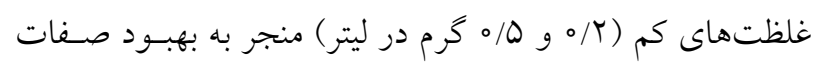

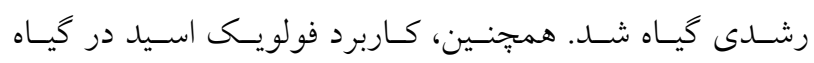

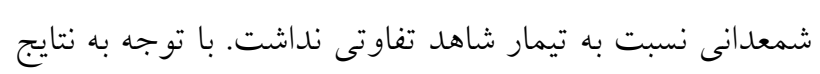

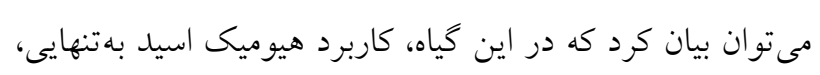
صفات مورد بررسى در اين آزمايش را نسبت به تيمار شـاهد و و ودياه

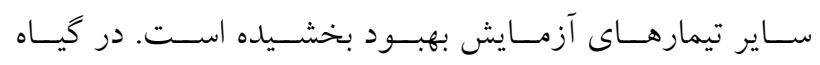

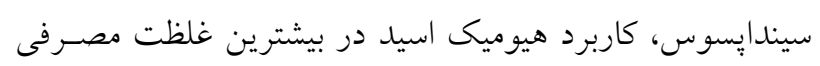

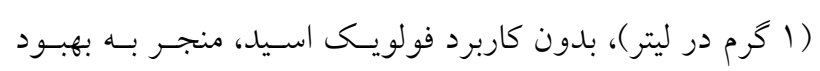

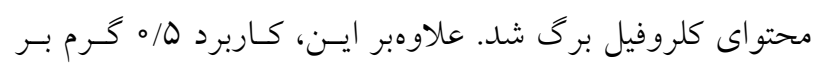

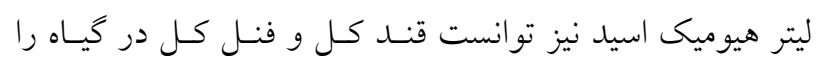

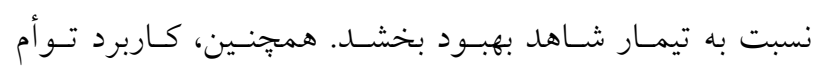

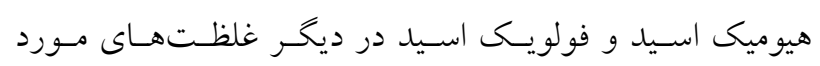

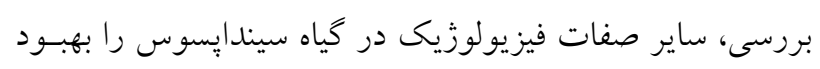

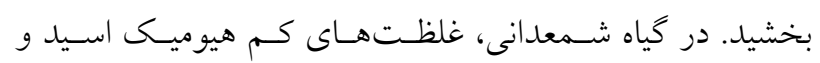

نشت الكتروليت در تيمار كاربرد توام هيوميك اسيد در غلظـت

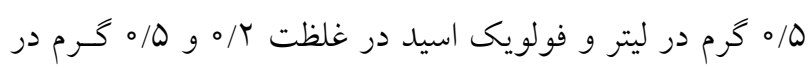

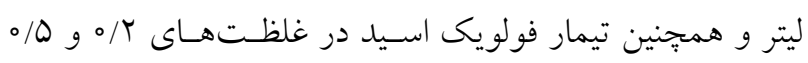

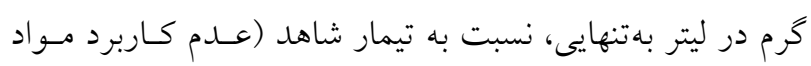

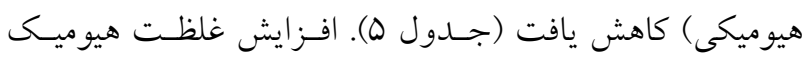

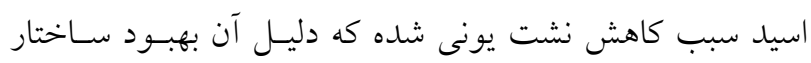

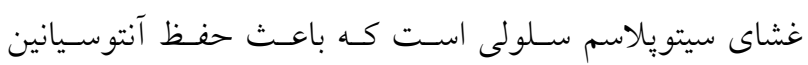

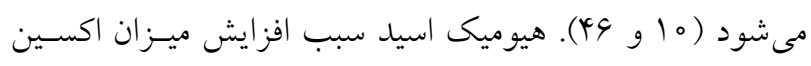

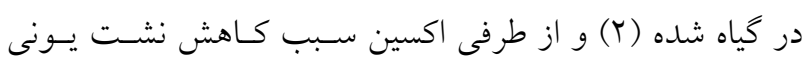

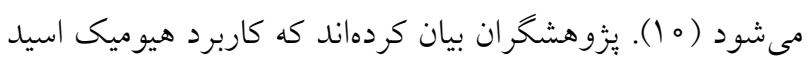

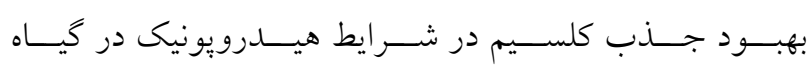

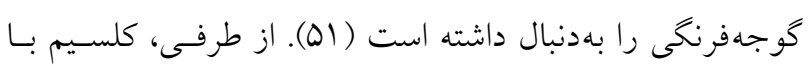

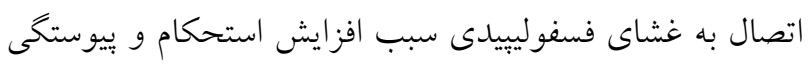

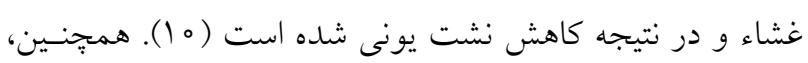

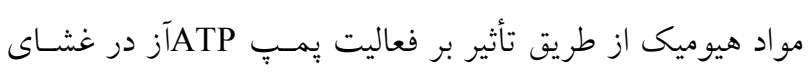

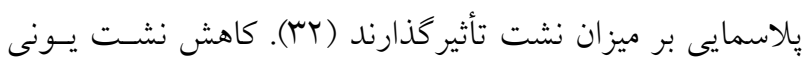

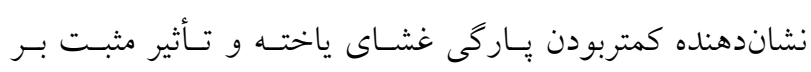

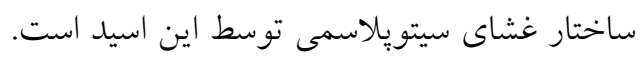

فنل كل

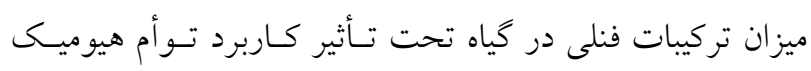

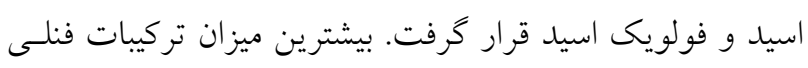

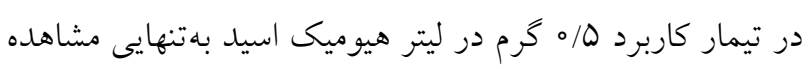
شد (جدول ه). فنوليكها گروهى از متابوليكهاى ثانويه هستند

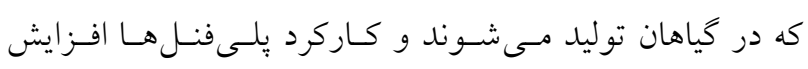

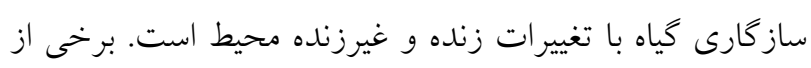

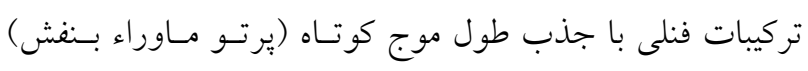

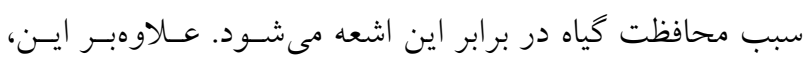

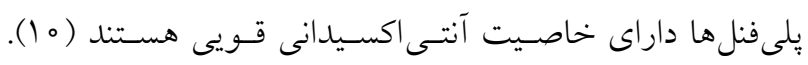

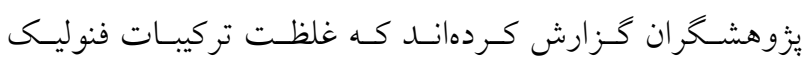

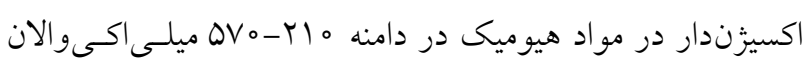

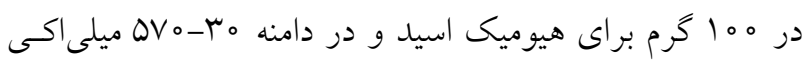




$$
\begin{aligned}
& \text { بيشترين غلظت فولويك اسـيد تـأثير بيشـترى نسـبت بـه سـاير با توجه به آثار مخرب و زيـانآور كودهـاى شـيميايى و كمبـود } \\
& \text { سطوح مورد استفاده در آزمايش داشتند. اين درحالى اسـت كـه عناصر مورد نياز كياه در خاك، امروزه استفاده از كودهـاى آلى لى }
\end{aligned}
$$

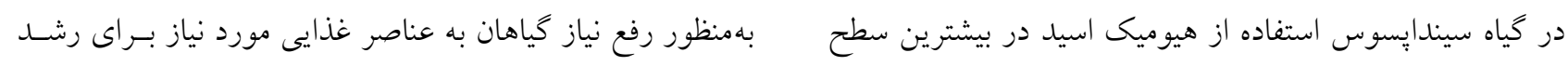

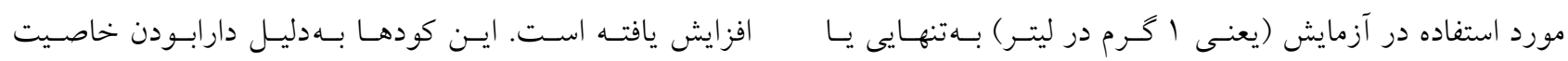

$$
\begin{aligned}
& \text { تركيب با سطوح يايين فولويك اسيد (T/ه و ه/ه گرم در ليتـر) هورمونى در مقادير كم آثار مشهود و مشخصى در بهبـود رشـد }
\end{aligned}
$$

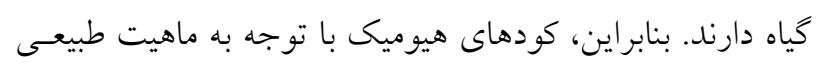

$$
\begin{aligned}
& \text { بودن، دوستدار محيطزيستبودن، تنوع در روش استفاده و بـا } \\
& \text { توجه به قيمت مناسب مىتوانند يكى از كودهاى مهم آلى باشند } \\
& \text { تا بهمنظور رفع نياز كودى گياه در دسترس گياه قرار گيرند. } \\
& \text { توانست صفات مورد بررسى را نسـبت بـه تيمـار شـاهد بهبـود } \\
& \text { بخشد. بهطور كلى، كاربرد هيوميك اسيد در دو گياه شمعدانى و }
\end{aligned}
$$

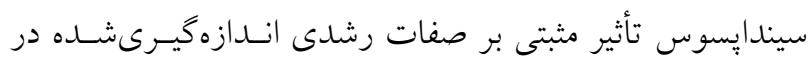

$$
\begin{aligned}
& \text { آزمايش داشت. فولويك اسيد نيز در غلظتهاى كــم در كـاربرد } \\
& \text { توأم با هيوميك اسيد تأثير مثبتى بر صفات رشدى گيساه داشـت. }
\end{aligned}
$$

\section{منابع مورد استفاده}

1. Abbaszadeh Faruji, R., M. Shoor, A. Tehranifar, B. Abedi and N. Safari. 2018. Effects of humic acid and fulvic acid on some morphological characteristics of geranium. J. Hort. Sci. 32: 35-50.

2. Abou-Aly, H.E. and M.A. Mady. 2009. Complemented effect of humic acid and biofertilizers on wheat (Triticum aestivum L.) productivity. Ann. Agric. Sci. Moshtohor. 47: 1-12.

3. Albayrak, S. and N. Camas. 2005., Effects of different levels and application times of humic acid on root and leaf yield and yield components of forage turnip (Brassica rapa L.). Agron. J. 4: 130-133.

4. Carrol, H.V., R.W. Longley and J.H. Roe. 1956. The determination of glycogen in liver and muscle by use of anthrone reagent. J. Biol. Chem. 220: 583-593.

5. Chamani, A., B. Esmaeilpoor, Y. Poor Beyrami Hir, H. Maleki Lejayer and A. Saadati. 2012. Effects of humic acid and thidiazouron on postharvest of alestromeria flower. J. Hort. Sci. 26: 147-152.

6. Chamani, E., D.C. Joyce and A. Reihanytabar. 2008. Vermicompost effects on the growth and flowering of Petunia hybrida 'Dream Neon Rose'. Am. Euras. J. Agric. Environ. Sci. 3: 506-512.

7. Davoodi Fard, M., D. Habibi and F. Davoodi Fard. 2012. Effects of salt stress on cell membrane stability, chlorophyll, and yield components in wheat inoculated with PGPR and Fulvic acid. Agron. J. 8: 71-86.

8. Dere, S., T. Gines and R. Sivaci. 1998. Spectrophotometric determination of chlorophyll a, b and total carotenoied content of some algae species using different solvents. Tr. J. Bot. 22: 13-17.

9. Develin, R.M. 1975. Plant Physiology. $3^{\text {rd }}$ Ed., Affiliated East West Press, New Delhi, pp. 159-205.

10. Dolatian, N. 2013. The effect of humic acid on quantitative and qualitative characteristics of strawberry var. Selva under the greenhouse conditions. MSc. Thesis, Ferdowsi University of Mashhad. (In Persian)

11. Esringü, A., I. Sezen, B. Aytatli and S. Ercişli. 2015. Effect of humic and fulvic acids application on growth parameters in Impatiens walleriana L. Akademik Ziraat Dergisi 4: 37-42.

12. Fan, H.M., X.W. Wang and X. Sun. 2014. Effects of humic acid derived from sediments on growth, photosynthesis and chloroplast ultrastructure in chrysanthemum. Sci. Hort. 177: 118-123.

13. Fatemi, H., A. Ameri, M.H. Amini Fard and H. Aroui. 2011. The effect of humic acid on essences and vegetative characteristics of basil. The First National Conference on New Issues in Agriculture, Islamic Azad University, Saveh. (In Persian)

14. Ghasemi, M., B. Kashefi and A. Matlabi. 2013. Reduction of salinity stress in ornamental plants using the effect of humic acid. Passive defense in the Agricultural Sector. Qeshm Island.

15. Ghasemi Ghahsareh, M. and M. Kafi. 2010. Scientific and Practical Floriculture. Vol. 1, 310 p. (In Persian)

16. Ghasemi Ghahsareh, M. and M. Kafi. 2010. Scientific and Practical Floriculture. Vol. 2, 310 p. (In Persian)

17. Kamali, M. 2012. Studying the effect of salt stress on physio-morphological characteristics of C4 plants Gomphrena globosa L. and Amaranthus tricolor under different levels of carbon dioxide. MSc. Thesis, Ferdowsi University of Mashhad. (In Persian)

18. Karakurt, Y., H. Unlu and H. Padem. 2009. The influence of foliar and soil fertilization of humic acid on yield and quality of pepper. Plant Soil Sci. 59(3): 233-237. 
19. Khazai, H.R., A. Nezami, A. Eyshi Rezai, A.H. Saeednezhad and F. Poor Amir. 2012. Effect of concentration and type of humic material as a pretreatment on germination and seedling characteristics of two cultivars of triticale (Triticosecale hexaploide Lart.). J. Agric. Ecol. 4: 273-281.

20. Krishnamoorthy, R.V. and S.N. Vajranabhiah. 1986. Biological activity of earthworm casts: An assessment of plant growth promotor levels in casts. Anim. Sci. 95: 341-350.

21. Li, G. and M.R. Evens. 2000. Humic acid substrate treatments and foliar spray application effects on root growth and development of seedlings. Hort. Sci. 35: 427-434

22. Mafakheri, S. 2017. Effect of some organic and chemical fertilizers on morphological and biochemical factors of Fenugreek (Trigonella foenum-graecum L.). J. Plant Prod. 40: 27-40.

23. Marcum, K.B. 1998. Cell membrane theromotability and whole-plant heat tolerance of Kentucky bluegrass. Crop Sci. 38: 1214-1218.

24. McDonald, S., P.D. Prenzler, M. Autolovich and K. Robards. 2001. Phenolic content and antioxidant activity of olive extracts. Food Chem. 73: 73-84.

25. Memon, S.A., F.M. Bangulzai, M.İ. Keerio, M.A. Baloch and M. Buriri. 2014. Effect of humic acid and iron sulphate on growth and yield of zinnia (Zinnia elegans). J. Agric. Sci. Technol. 10(6).

26. Nardi, S., D. Pizzeghello, A. Muscolo and A. Vianello. 2002. Physiological effects of humic substances on higher plants. Soil Biol. Biochem. 34: 1527-1536.

27. Nasiri, S. 2013. Studying the effect of humic acid and yeast (Saccharomyses cerevisiae) on morphological and phytochemical characteristics of European Borage (Borago officinalis L.) under two levels of manure. MSc. Thesis, Ferdowsi University of Mashhad. (In Persian)

28. Neri, D., E.M. Lodolini, M. Luciano, P. Sabbatini and G. Savini. 2002. The persistence of humic acid droplets on leaf surface. International Symposium on Foliar Nutrition of Perennial Fruit Plants, ISHS. Acta Hort. 594: $303-314$.

29. Nikbakht, A., M. Kafi, M. Babalar, N. Etemedi, H. Ebrahimzadeh and S.Y. Ping. 2007. The effect of humic acid on calcium absorption and postharvest physiological behaviors of Gerbera. Int. J. Hort. Sci. Technol. 8: $237-248$.

30. Nikbakht, A., M. Kafi, M. Babalar, P.Y. Xia, A. Luo and N. Etemadi. 2015. Effect of humic acid on plant growth, nutrient uptake, and postharvest life of gerbera. J. Plant. Nutr. 31: 2155-2167.

31. Noori Hosseini, S., Z. Khogar and A. Ahmad Pour. 2007. Effective use of organic fertilizers in tomato cultivation. First Congress of Tomato Processing Technologies, Feb. 16, Mashhad.

32. Pinton, R., S. Cesco, G. Iacolettig, S. Astolfi and Z. Varanini. 1999. Modulation of $\mathrm{NO}_{3}$ uptake by water extractable humic substances: Involvement of root plasma membrane $\mathrm{H}^{+}$ATPase. Plant Soil 215: 155-161.

33. Rauthan, B.S. and M. Schnitzer. 1981. Effects of soil fulvic acid on the growth and nutrient content of cucumber (Cucumus sativus) plants. Plant Soil 63: 491-495.

34. Roohani, N.S. 2014. The role of humic acid in morphological, physiological and biochemical characteristics of three varieties of radish (Raphanus sativus L.) under salt stress. MSc. Thesis, Ferdowsi University of Mashhad. (In Persian)

35. Roosta, H.R., M. Hosseinkhani and M. Vakili Shahrbabaki. 2016. Effects of foliar application of nano-fertile fertilizer containing humic acid on growth, yield and nutrient concentration of mint (Mentha sativa) in aquaponic system. J. Sci. Technol. Greenhouse Culture 6(24): 1-10.

36. Saadati, J. and M. Baghi. 2014. Evaluation of the effect of various amounts of humic acid on yield, yield components and protein of chickpea cultivars (Cicer Arietinum L.). Int. J. Adv. Biol. Biomed. Res. 2: $2306-2313$.

37. Sabzevari. S., H.R. Khazai and M. Kafi. 2010. Effects of humic acid on germination of four varieties of winter wheat (Sayonez and Sabalan) and spring wheat (Chamran and Pishtaz). Agric. Res. J. 8: 473-480.

38. Salehi, B., A. Bagherzadeh, M. Ghasemi and M. Ebrahimi. 2010. The effect of organic matter of humic acid on the growth characteristics, yield and yield components of three varieties of tomato (Lycopersicon esculentum L.). J. Agric. Ecol. 2: 640-647.

39. Samavat, S. 2007. Study of the amount of humic acid in different organic materials and the effect of humic acid of urban waste compost on some soil properties. Iranian Soil Science Congress, Karaj. (In Persian)

40. Sanchez-Sanchez, A., J. Sanchez-Anderu, M. Juarez, J. Jorda and D. Bermudez. 2002. Humic substances and amino acid improve effectiveness of chelate FeEDDHA in lemons trees. J. Plant. Nutr. 25: 2433-2442.

41. Sardashti, A.R. and M. Alidoost. 2007. Determining and identifying of humic acid compounds in forest soils of north of Iran. Fifteenth Congress of Crystallography and Mineralogy of Iran, Ferdowsi University of Mashhad, Mashhad. (In Persian)

42. Shah Hoseeini, Z., A. Gholami and H.R. Asghari. 2012. The impact of mycorrhizal symbiosis and the use of humic acid on water use efficiency and physiological indicators of corn growth under irrigation deficit. J. Dry Canvas 2(1): 39-56.

43. Shahbazi, Sh., E. Fateh and A. Aynehband. 2015. Evaluation of the effect of humic acid and vermicompost on yield and yield components of three wheat cultivars in tropical regions. J. Plant Prod. 38(2): 99-110. 
44. Shahsavan Markade, M. and A. Chamani. 2014. Effect of different concentrations and times of humic acid application on quantitative and qualitative characteristics of mattiola cut flowers, 'Hanza' cultivar. J. Agric. Sci. Technol. 5(19): 157-170.

45. Shariati Nia, F., A.R. Karimi Goghari, N. Soltani Nezhad and M. Shamsodin Saeed. 2012. Assessing the effect of humic acid and salinity on vegetative growth and some physiological characteristics of cotton (Var. Varamin). The Second National Conference on Advances in Crop Plants, Islamic Azad University, Bojnoord. (In Persian)

46. Sharif, M., R.A. Khattak, and M.S. Sarir. 2002. Effect of different levels of lignitic cool derived humic acid on growth of maize plants. Commun. Soil Sci. Plant Anal. 33: 3567-3580.

47. Shekari, H., A. Roozbehani and S. Safari Dolatabad. 2013. Study of the effect of humic acid and fulvic acid and different levels of nitrogen on physiological and quantitative traits of Ricinus commonis. National Conference of Passive Defense in Agriculture, Qeshm Island, Iran.

48. Sladky, Z. and V. Tichy. 1959. Applications of humus substances to overground organs of plants. Biol. Plant. 1: 915.

49. Tehrani, A. 2014. The effect of foliar application of humic substances on some quantitative and qualitative characteristics of strawberry var. Camarosa. PhD Dissertation, Ferdowsi University of Mashhad, Mashhad, Iran. (In Persian)

50. Tejada, M. and J.L. Gonzalez. 2003. Influence of foliar fertilization with amino acids and humic acids on productivity and quality of asparagus. Biol. Agric. Hort. 21(3): 277-291.

51. Türkmen, Ö., A. Dursun, M. Turan and C. Erdinç. 2004. Calcium and humic acid affect seed germination, growth, and nutrient content of tomato (Lycopersicon esculentum L.) seedlings under saline soil conditions. Acta Agric. Scand. 7: 168-174.

52. Visser, S.A. 1986. Effect of humic substances on plant growth. PP. 161-186. In: MacCarthy, P., C.E. Clapp, R.L. Malcolm and P.R. Bloom (Eds.), Humic Substances Effect on Soil and Plants, ASA and SSSA, Mad., WI.

53. Visser, S.A. and M. Caillier. 1988. Observations on the dispersion and aggregation of clays by humic substances: I. Dispersive effects of humic acids. Geoderma 42: 331-337.

54. Xu, X. 1986. The effect of foliar application of fulvic acid on water use, nutrient uptake and wheat yield. Aust. J. Agric. Res. 37: 343-350.

55. Yang, C.M., C.W. Ming, Y.F. Lu, I.F. Chang and C.H. Chou. 2004. Humic substances affect the activity of chlorophylls. J. Chem. Ecol. 30: 5.

56. Zhang, J.M., S.J. Xing, M.P. Sang, B.Y. Ma, X.M. Chu and C.S. Liu. 2010. Effect of humic acid on poplar physiology and biochemistry properties and growth under different water level. J. Soil Water Conserv. Vol. 6: 42. 


\title{
Effects of Humic and Fulvic Acids on Some Physiological Characteristics of Two Ornamental Plants of Granium (Plargonium spp.) and Scindapsus (Scindapsus spp.)
}

\author{
R. Abbaszadeh Faruji ${ }^{1}$, M. Shoor ${ }^{1 *}$, A. Tehranifar ${ }^{1}$ and B. Abedi ${ }^{1}$
}

(Received: 5 August. 2018; Accepted: 15 May 2018)

\begin{abstract}
Humic acid and fulvic acid are natural and organic materials, which are derived from various sources such as soil organic matter (humus), soil, peat, oxidized lignite and coal. In order to evaluate the effect of humic substances on physiological characteristics of two ornamental plants of granium (Plargonium spp.) and scindapsus (Scindapsus spp.), an experiment was conducted as $4 \times 4$ factorial, based on completely randomized design with three replications, in Research Greenhouse of Ferdowsi University of Mashhad during 2014-2015. The first factor was four levels of humic acid $(0,0.2,0.5$ and $1 \mathrm{~g} / \mathrm{L})$ and the second factor was fulvic acid at four levels $(0,0.2,0.5$ and $1 \mathrm{~g} / \mathrm{L})$. Results showed that the use of humic acid and fulvic acid caused an improvement in most measured physiological traits in geranium and scindapsus. In granium plant, application of humic acid at low concentration could improve plant growth characteristics. The content of chlorophyll and stomatal conductance in granium increased by humic acid application $(0.2$ and $0.5 \mathrm{~g} / \mathrm{L})$ as fertigation compared to control treatment. Combined application of humic acid and fulvic acid in this plant, also improved soluble sugar content of the plant and reduced the electrolyte leakage as compared to control. In scindapsus, using humic acid at the highest concentration, solely or in combination with fulvic acid, resulted in the improvement of growth traits, so that the combination of humic acid and fulvic acid resulted in increased soluble sugar and SPAD index in this plant. Moreover, chlorophyll content of the plant was increased by the application of humic acid $(1 \mathrm{~g} / \mathrm{L})$ as fertigation in comparison with the control treatment. These compounds increase plants' growth by improving their growth conditions. According to the results of this study, application of humic acid and fulvic acid as organic fertilizers is recommended for improving growth in geranium and scindapsus ornamental plants.
\end{abstract}

Keywords: Organic fertilizers, Growth traits, Chlorophyll content, Stomatal conductance.

1. Dept. of Hort. Sci. and Landscape Eng., College of Agric., Ferdowsi Univ., Mashhad, Iran.

* Corresponding Author, Email: shoor.ferdowsi@um.ac.ir 